\title{
Developments in the field of allergy in 2014 through the eyes of Clinical and Experimental Allergy
}

\author{
B. J. Hales, N. Hizawa, Maria Jenmalm, E. Sverremark-Ekstroem and A. J. Wardlaw
}

\section{Linköping University Post Print}

\section{Tweet}

N.B.: When citing this work, cite the original article.

Original Publication:

B. J. Hales, N. Hizawa, Maria Jenmalm, E. Sverremark-Ekstroem and A. J. Wardlaw, Developments in the field of allergy in 2014 through the eyes of Clinical and Experimental Allergy, 2015, Clinical and Experimental Allergy, (45), 12, 1723-1745.

http://dx.doi.org/10.1111/cea.12663

Copyright: Wiley: 12 months

http://eu.wiley.com/WileyCDA/

Postprint available at: Linköping University Electronic Press

http://urn.kb.se/resolve?urn=urn:nbn:se:liu:diva-123509 
Developments in the field of allergy in 2014 through the eyes of Clinical and Experimental Allergy

${ }^{1}$ Hales, B.J. ${ }^{2}$ Hisawa, N. ${ }^{3}$ Jenmalm, M.C. ${ }^{4}$ Wardlaw, A.J.

${ }^{1}$ Telethon Kids Institute, The University of Western Australia, Perth, Australia.

${ }^{2}$ Department of Respiratory Medicine, Faculty of Medicine, University of Tsukuba, Japan

${ }^{43}$ Department of Clinical and Experimental Medicine, Unit of Autoimmunity and Immune

Regulation, Division of Clinical Immunology, Linköping University, SE-581 85 Linköping,

Sweden

${ }^{4}$ Institute for Lung Health, Department of Infection Immunity and Inflammation, University of

Leicester and Department of Respiratory Medicine, University Hospitals of Leicester NHS Trust

$\underline{\text { Address for Correspondence }}$

Professor Andrew Wardlaw

Institute for Lung Health

Glenfield Hospital

Groby Road

Leicester LE 9QP

aw24@le.ac.uk

44 (0)116 2583841 
$\underline{\text { Acknowledgements }}$

AJW is part funded by the Leicester NIHR Respiratory Biomedical Research Unit. The opinions expressed in this article are not necessarily those of the NIHR.

\section{Abbreviations.}

AHR: $\quad$ Airway hyperresponsiveness

CRSsNP: $\quad$ Chronic rhinosinusitis without nasal polyps

CRSwNP: Chronic rhinosinusitis with nasal polyps 


\section{Summary}

The pathogenesis of asthma continues to be a major topic of interest to our authors with reviews and original papers on the role of viruses, mechanisms of inflammation, biomarkers and phenotypes of asthma being major topics. A number of papers described new treatments for asthma focusing on blocking the Th2 response reflecting the fact that two decades of work in this area is finally bearing fruit. The pathogenesis of chronic rhinosinusitis is a growing area of interest, but there has been less on the genetics of airways disease than in previous years possibly reflecting the degree of rigour (and therefore a smaller body of work), with which these sorts of studies are now being undertaken. There continues to be a wide range of papers dealing with mechanisms of allergic disease ranging from clinical based studies to basic research and the use of in vivo animal models especially mice. As before mechanisms and new approaches to immunotherapy are common themes. Several were published in the allergens section investigating modification of allergens to increase their effectiveness and reduce the risk of adverse events. Risk factors for allergic disease was a common theme in the epidemiology section and food allergy a common theme in clinical allergy with papers on the development of protocols to induce tolerance and attempts to find biomarkers to distinguish sensitization from allergic disease. Another exciting year for the editors and we hope the readers of the journal. 


\subsection{Asthma and Rhinitis}

1.1 Phenotypes of the disease

For the past several decades, asthma was considered a homogeneous disease caused by allergeninduced, Th2-driven, eosinophilic airway inflammation. However, in recent years, clinical and translational research has demonstrated that asthma is highly heterogeneous in character and varies in severity, clinical expression, and treatment response between individuals and within individuals over time. For example, using both biased and unbiased approaches, multiple asthma phenotypes have been described in relation to such factors as eosinophilic inflammation, exacerbation and age at onset; these phenotypic analyses have improved our understanding of the heterogeneity of asthma and may provide a starting point to transform clinical practice through evidence-based classification of disease severity.

The nature of young adult wheezing has yet to be clearly characterized. Kurukulaaratchy and colleagues used cluster analysis to define clinically relevant young adult wheeze clusters in a longitudinal birth cohort (1). K-means cluster analysis was undertaken among 309 currently wheezing subjects aged 18 years in the Isle of Wight birth cohort $(\mathrm{N}=1456)$. Using 13 parameters representing core disease characteristics, the study identified six wheeze clusters at 18 years with differing associations with age of wheezing onset, atopy, allergic co-morbidity, lung function, bronchodilator reversibility (BDR), airway hyper-responsiveness (AHR), and level of asthma therapy. Further characterization of those clusters indicated differing associations with 
healthcare utilization, symptom severity, and frequency. More severe clusters were associated with childhood onset, atopy, impaired lung function, and smoking, and merit additional attention.

Although disease phenotypes are the result of complex interactions between largely unknown genetic and environmental mechanisms, identification of environmental factors offers a real possibility of asthma prevention. Gonzalez and colleagues analyzed associations between asthma and occupational exposure to disinfectants, especially quaternary ammonium compounds (QACs), which are commonly used in cleaning/disinfection products (2). Nursing professionals reported a significantly higher risk of reported physician-diagnosed asthma and, for registered nurses, of nasal symptoms at work than did administrative staff working in the health-care sector. This risk was particularly marked during disinfection tasks and during exposure to QACs. The highest risk was associated with tasks involving dilution of disinfection products by manual mixing, suggesting possible exposure to repeated peaks of concentrated products known to be strong respiratory irritants. Workplace interventions should be conducted to more clearly determine QAC exposure and improve disinfection procedures.

\subsection{Eosinophilic inflammation}

Molfino and coworkers reviewed the literature in 2012 showing that sputum eosinophilia can be used to predict severe exacerbations and response to corticosteroid therapy and anti-eosinophil therapies such as anti-IL-5 (3). Despite this, measurement of airway inflammation using sputum 
analysis has not found its way into routine management and remains primarily a research tool.

Zhang and colleagues found that blood eosinophil count, whether expressed as a percentage or a number, is a sensitive and specific marker of a raised sputum eosinophil count (4). Cianchetti and colleagues assessed whether sputum eosinophils and sputum eosinophil cationic protein (ECP) were related differently to several clinical and functional parameters (5). Patients were divided into four groups on the basis of sputum eosinophil percentage and sputum ECP values. The results confirmed that the pattern of airway inflammation is heterogeneous in asthma. Overall, both increased sputum eosinophils and increased ECP levels were related to increasing severity of clinical presentation assessed by asthma symptom score and use of short-acting bronchodilators. An interesting finding was the poor concordance between the two indices of airway eosinophilia, ie, percentage of eosinophils and ECP levels, with discordant results in $38.8 \%$ of the cases.

Considering both markers, the proportion of mild/moderate asthmatic patients without evidence of airway eosinophilia was limited to $20 \%$. A stepwise regression analysis showed weak, albeit significant, inverse correlations between eosinophil count and disease duration, and between ECP and airflow obstruction, suggesting that these biomarkers might identify different aspects of the disease.

\subsection{Asthma exacerbation}

Exacerbations represent a major source of morbidity and mortality in asthma and are a prominent feature of poorly controlled, difficult-to-treat disease. Factors that cause and/or trigger asthma 
attacks include host-related factors (genetic predisposition, obesity, and sex) and environmental factors (allergens, infections, occupational sensitization, smoking status, pollution, and diet). Kupczyk and colleagues, by studying 93 patients with severe asthma and 76 patients mild-tomoderate asthma, were able to distinguish and characterize a sub-phenotype of asthma patients - frequent exacerbators, who were significantly more prone to exacerbations (6). The study showed that patients with FeNO $>45 \mathrm{ppb}$ and a history of smoking are at increased risk of frequent exacerbations and require careful monitoring in clinical practice.

\subsection{Adult-onset asthma}

Many people develop asthma in childhood. However, asthma symptoms can appear at any time in life. Although the prevalence of asthma in the elderly is increasing and is associated with higher mortality than in children or young adults, the effect of older age on airway inflammation in asthma is not well established. Brandenberger and colleagues, used 12-week-old and 15-monthold male BALB/c mice, sensitized and challenged with house dust mite (HDM), and indicated that elderly patients with asthma may be prone to developing severe allergic airway inflammation with a mixed Th2/Th17 immune response (7). The features of allergic airway disease, such as mucous cell hyperplasia, infiltration of airway eosinophils and lymphocytes and Th2 cytokine expression, were greater in the old than in the young mice. In addition, only the old mice developed airway neutrophil infiltration and a Th 17 immune response upon HDM exposure, with increases in the BALF cytokines IL-17A and KC and in Th17 cytokine-producing T cells in the 
spleen, suggesting that the severity and character of allergic airway disease are age-dependent, with a bias towards a Th17 immune response with aging. Birmingham and colleagues also noted age-specific differences in the effect of a viral infection on allergic sensitization, airway inflammation, and AHR between young and old mice infected with a non-lethal dose of influenza virus A (8). Serum OVA-specific IgE was significantly increased only in the old mice infected with influenza virus. Therefore, in a mouse model, viral infection prior to antigen sensitization affects the airway and systemic allergic responses differently according to increase in age. These differences may reflect distinct phenotypic features of allergic inflammation in older patients with asthma.

Recent studies suggested that Staphylococcus aureus enterotoxin sensitization is a risk factor for asthma (9). Using a baseline data set from a Korean adult population survey, consisting of 1080 adults recruited from an urban and a rural community, Song and colleagues identified Staphylococcalsp. enterotoxin sensitization as having a prevalence of $27.0 \%$, and the risk factors as being male sex, current smoking, advanced age and inhalant allergen sensitization (10). Staphylococcalsp. enterotoxin sensitization was independently associated with adult-onset asthma in the adult community population.

1.5 Hygiene hypothesis 
According to the hygiene hypothesis, changes in lifestyle in industrialized countries have led to a decrease in the infectious burden and are associated with a rise in allergic diseases (11).

Underlying mechanisms include immunoregulation, involving various regulatory $\mathrm{T}$ cell subsets and Toll-like receptor stimulation, which could originate from changes in the microbiota caused by changes in lifestyle. Recent reports indicate that a high diversity of the gut microbiota in infancy may be more important than the prevalence of specific bacterial taxa (12). The suggested underlying rationale is that the gut immune system reacts to exposure to new bacterial antigens and repeated exposure enhances the development of immune regulation including a conversion of CD4+ T cells into regulatory T cells. Abrahamsson and colleagues assessed microbial diversity and characterized the dominant bacteria in stool during the first year of life in relation to the prevalence of different allergic diseases according to school age, such as asthma, allergic rhinitis (AR), and eczema (13). The microbial diversity and composition were analyzed with barcoded $16 \mathrm{~S}$ rDNA 454 pyrosequencing in stool samples at the ages of 1 week, 1 month, and 12 months in 47 infants, who were subsequently assessed for allergic disease and skin prick test reactivity at the age of 7 years. Children who developed asthma had a lower diversity of the total microbiota than did non-asthmatic children at 1 week and 1 month of age, whereas AR, eczema, and positive skin prick reactivity at 7 years of age was not associated with gut microbiota diversity. Children having IgE-associated eczema in infancy and subsequently developing asthma had lower microbial diversity than did those who did not. 
Cheng and colleagues evaluated the independent and combined effects of day care attendance and respiratory infections on the development of asthma at the age of 7 in a prospective birth cohort (14). Day care hours and number of respiratory infections were reported in follow-up questionnaires through age 4 . At 7 years of age, asthma was diagnosed in 95 children (16\%), on the basis of predefined symptoms criteria confirmed by the presence of either BDR or AHR. In the multivariate logistic model, the cumulative hours of day-care attendance and number of lower respiratory infections at 12 months were associated with asthma. However, a threshold of greater than 37.5 hours per week of day-care attendance was associated with a lower risk of asthma. Dependent on the duration of attendance, day care during infancy can either increase or reduce the risk of asthma at the age of 7 .

1.6 Chronic rhinosinusitis with nasal polyps

Two studies from Japan and China reported distinct patterns of inflammation in eosinophilic and non-eosinophilic chronic rhinosinusitis with nasal polyps (CRSwNP). The concentrations of total $\mathrm{IgE}$ and number of IgE-positive cells were significantly higher in the eosinophilic polyps than in the non-eosinophilic polyps. IgE-positive cells were predominantly mast cells in the eosinophilic polyps and significantly correlated with the number of FceR1-positive cells in the sub-epithelial layer. IL-5 and IL-13 mRNA and $\varepsilon$ germline gene transcript expression levels were also significantly higher in the eosinophilic polyps than in the control and non-eosinophilic polyps (15). The number of mast cells positive for both tryptase and chymase and of activated mast cells 
was increased in eosinophilic CRSwNP, and the number of activated mast cells was positively correlated with local IgE level, eotaxin-1 level and eosinophil count in CRSwNP (16). These studies suggest local class switching to IgE, production of IgE, and IgE localization to the surface of mast cells in eosinophilic chronic rhinosinusitis. The difference in the IgE-related profiles between eosinophilic chronic rhinosinusitis and non-eosinophilic chronic rhinosinusitis offers a rationale for considering intervention strategies designed to target local allergy in eosinophilic CRSWNP.

\subsection{Rhinitis and Airway Hyperresponsiveness}

A high percentage of patients with AR exhibit signs of AHR, and approximately $30 \%$ may develop asthma later in life. Buslau and colleagues identified predictors for allergen-induced asthma in patients with AR (17). Bronchial allergen provocation (BAP) is considered the gold standard for the diagnosis of clinically relevant allergen-specific asthma. An early asthmatic reaction was equally distributed between patients with and without signs of possible asthma as assessed by questionnaire (56.8\% vs. $48.3 \%)$. There is a considerable discordance between reported asthma signs and disease diagnosed by BAP. Simple measurement of allergen-specific IgE for grass pollen was the best predictor of allergen-induced asthma in patients with AR.

Exercise-induced bronchospasm (EIB) is frequent among asthmatic children. Caillaud and colleagues assessed the relationship between EIB and various phenotypes of rhinitis according to 
asthmatic status at the general population level in the Six Cities Study (18). Of 6813

schoolchildren, 227 (3.33\%) experienced EIB after exercise. In this large sample of 10-year-old children drawn from the general population, EIB was associated with rhinitis in the absence of asthma. Furthermore, it constituted an entity independent of asthma and was not related to a familial history of asthma. Thus investigating these symptoms could be important in this disease, as a specific nasal treatment might improve EIB in these children.

\subsection{Genetics/epigenetics}

Studies of genetics and epigenetics could give us some idea about the endotype of asthma, ie, a sub-type of the condition defined by a distinct pathophysiological mechanism underlying several phenotypes. An insight related to the role of filaggrin mutations was reported in the population cohort established in the Isle of Wight in the UK (19). Filaggrin is a barrier protein in the skin, and loss of function genetic mutations in filaggrin is a major risk factor for eczema. Although filaggrin is not expressed in the airway, it is also an important risk factor for asthma and AR and particularly a combination of all three 'atopic' diseases. People with mutations in the filaggrin gene have a 23-fold increased risk of developing a combination of eczema, asthma, and AR. The mechanism is likely related to the loss of barrier function leading to sensitization via the skin that favors a Th2-type immune response. This generates specific IgE that then interacts with inhaled allergens leading to allergic disease of the airways. 
Yatagai and colleagues reported the results of a sub-analysis of a larger Japanese GWAS in an article published in 2011(20,21). This larger GWAS identified five loci at a genome-wide significant threshold for asthma in 7171 adult individuals with asthma and 27,912 controls. These patients were recruited from different regions of Japan. In their sub-analysis, 240 asthma patients and 734 healthy controls recruited in a single region were analyzed for a genome-wide association with asthma. Only participants from one specific geographic region were selected, the rationale being that certain polymorphisms may be more present or important in a certain region. Furthermore, only non-smoking asthmatic patients or those with a limited smoking history of less than 10 pack years were included. This may have reduced the number of participants who had asthma-like symptoms due to environmental factors such as smoking, and increased the power to find genetic effects. Using this approach, evidence for a gene called hyaluronan synthase 2 (HAS2) was provided. This gene encodes a glucosaminoglycan that is present in the extracellular matrix and is strongly expressed in the lungs. Furthermore, asthma-associated SNP was shown to regulate the mRNA expression of HAS2. This genetic association signal was not found in the initial larger Japanese GWAS, suggesting that the selection of one geographic region was important. It is also plausible that smoking strongly affected their results.

Tryptase, a major secretory product of human mast cells, has been implicated as a key mediator of allergic inflammation. Genetic variation in the tryptases is extensive, and $\alpha$-tryptase, an allelic variant of the more extensively studied $\beta$-tryptase, is absent in substantial numbers of the general 
population. Abdelmotelb and colleagues investigated the $\alpha$-tryptase gene copy number variation and its potential associations with asthma phenotypes (22). White families $(n=341)$ with at least two asthmatic siblings $(n=1350)$ were genotyped for the $\alpha$-tryptase alleles. Associations between $\alpha$-tryptase copy number and serum IgE levels, atopy scores, and bronchial function were found, indicating roles for tryptases in regulating IgE production and other processes in asthma.

Epigenetic dysregulation manifested by DNA methylation, potentially reflecting combined genetic and environmental modulation, has been reported in asthma and allergy (23). Genetic variation in the $\beta-2$ adrenergic receptor gene (ADRB2) has been implicated in asthma severity and control, with conflicting results. Epigenetic variation in ADRB2 may play an important role in the asthma phenotypes. Gaffin and colleagues found that DNA methylation in ADRB2 was associated with decreased asthma symptom severity, suggesting a role for methylation in asthma phenotypes in inner-city school-aged children (24).

1.9 Biology of allergic inflammation underlying asthma and rhinitis

T lymphocytes, particularly Th2 cells, are critical to the development and maintenance of asthma. However, the factors responsible for regulating the development and/or maintenance of Th2mediated inflammation are not well understood. Many studies have explored the cellular and molecular mechanisms involved in asthma and allergic diseases 
IL-21-positive cells are increased in the bronchial mucosa of asthmatic patients when compared with those of non-asthmatic individuals. Allergic airway responses were compared in wild-type and I121R-deficient mice exposed to local airway challenge with HDM (25). The study demonstrated that IL21R-deficiency reduces HDM-driven AHR with only partial effects on airway inflammation. Concomitant with the reduction in AHR in I121R-deficient mice, significant suppression was observed in the protein levels of the Th2 cytokines IL-4 and IL-13. The study indicated that IL-21 plays an important role in allergic diathesis by enhancing Th2 cytokine production through multiple mechanisms, including the suppression of Treg inhibitory effects on Th2 cytokine production.

IL-25 has also been implicated in the pathogenesis of asthma as a result of studies on human subjects with asthma and on murine asthma models. Compared with the OVA-challenge, intranasal challenge of BALB/c mice with IL-25 alone induced a delayed, predominantly eosinophilic and lymphocytic infiltration into the airway lumen, along with increased production of Th2-type cytokines, chemokines and collagen, secretion of epithelial mucus, goblet cell hyperplasia, deposition of sub-epithelial collagen, airway smooth muscle cell hyperplasia, and angiogenesis(26). In contrast, IL-25 exposure did not increase IgE or IgG1 production. This study suggested that chronic airway exposure to IL-25 alone is sufficient to induce allergen- and IgEindependent, asthma-like airway inflammation, remodeling, and hyper-responsiveness in mice. 
Dendritic cells (DCs) are professional antigen-presenting cells that mediate the response to inhaled allergens. A major division in DC ontogeny exists between myeloid DCs (mDCs) and plasmacytoid DCs (pDCs). Peripheral blood and induced sputum were obtained before and at 3, 7 and $24 \mathrm{~h}$ after inhalation of diluent and allergen from allergic asthmatic patients who developed both allergen-induced early- and late-phase responses. A sub-type of mDCs expressing thrombomodulin, termed myeloid DCs type 2 (mDC2s), has been identified in both the circulation and lungs and has recently been suggested to have a role in allergic asthma. Dua and colleagues found that the number of sputum mDC2s significantly increased $24 \mathrm{~h}$ after allergen challenge when compared with after diluent challenge in patients with asthma, suggesting that this subtype of $\mathrm{mDC}$ is involved in the regulation of allergen responses in the lung (27).

In $\mathrm{AR}$, it has been shown that ICOS expression is up-regulated and associated with Th2 response (28). mDCs from AR patients expressed a lower level of ICOSL, in both blood and nasal tissue. mDCs from AR were constitutively primed to induce Th2 cytokines and TNF in allogeneic CD4+ T cells. Shen and colleagues showed that mDCs from patients with AR displayed impaired ICOSL expression, and that this defect licenses mDCs to promote aberrant IL-13-and IL-5-producing Th2-cell responses (29).

Inhaled peptide challenge has been shown to induce a T cell-mediated, isolated late asthmatic reaction (LAR), characterized by recruitment of CD4+ T cells. Epithelial-derived thymic stromal 
lymphopoietin (TSLP) has been shown to modulate dendritic cell function to promote Th2 responses. Both dsRNA and allergen-specific T cells induced enhanced TSLP secretion from asthmatic primary bronchial epithelial cells (PBECs) compared with healthy PBECs (30). IL-1 $\beta$, IL6, and CXCL8, rather than Th2 cytokines including IL-4, IL-5, and IL-13, appeared to be the principle mediators of allergen-specific T cell-dependent induction of epithelial-derived TSLP, which was regulated by the MEK, MAPK and NFKB pathways. This study revealed a novel effect of allergen-specific T cells as a positive regulator of TSLP production by epithelial cells, suggesting T cell-airway epithelium interactions that may lead to maintenance and amplification of allergic inflammation.

Regulatory T cells (Tregs) are activated during anergy in response to T cell receptor (TCR) activation and functional immune suppression. Negoro and colleagues reported that CD4+, CD25+, CD127-/low Tregs from participants without asthma did not elicit $\mathrm{Ca}^{2+}$ influx in response to TCR activation, exhibited little proliferation, and suppressed proliferation of CD4+, CD25- T cells (31). In contrast, under similar conditions, Tregs from patients with asthma exhibited increased $\mathrm{Ca}^{2+}$ influx and robust proliferation with partial loss of regulatory functions. They confirmed that Tregs in patients with asthma are functionally impaired and that the abnormal regulatory functions of these cells can be analyzed by $\mathrm{Ca}^{2+}$ influx following TCR engagement. Furthermore, their study indicated that the impaired functioning of Tregs evident in patients with asthma may be due to a high level of the receptor for activated C kinase 1 (RACK1). 
Regulatory B cells have been identified that strongly reduce allergic inflammation in experimental models by producing IL-10. van der Vlugt and colleagues analyzed peripheral blood B cells from 13 patients with allergic asthma and matched healthy controls for the expression of different regulatory B-cell markers (32). They showed that the $\mathrm{CD} 24^{\text {hi }} \mathrm{CD} 27+\mathrm{B}-\mathrm{cell}$ subset was reduced in number and that IL-10 production was decreased in patients in response to LPS. In response to DerP1, CD4+ T cells taken from patients and co-cultured with LPS-primed B cells produced less IL-10 than did similar cultures from controls. These results indicated that CD24hi $C D 27+B$ cells from allergic asthma patients produce less IL-10 in response to LPS, leading to weaker IL-10 induction in T cells in response to DerP1.

The presence of activated NK cells has also been noted in patients with asthma. Induction of OVAallergic airway disease (AAD) in C57BL/6 wild-type (WT) mice resulted in the expansion of airway NK cells and the development of pronounced airway eosinophilia. In the absence of NK cells or specific subsets of NK cells, either in NKD mice or after the depletion of Ly49A/D/G+ NK cells, the development of OVA-AAD was significantly impaired as seen by decreased airway inflammation and eosinophilia, decreased secretion of the Th2 cytokines IL-4, IL-5, and IL-13, and diminished OVA-specific antibody production (33). Furthermore, while OVA exposure induced a dramatic expansion of DCs in WT mice, their induction was significantly attenuated in 
NKD mice. These findings demonstrated that conventional NK cells play an important and distinct role in the development of $\mathrm{AAD}$.

IL-13, a helper Th2 cytokine, transforms cultured airway epithelial cells to goblet cells, and this is not inhibited by corticosteroids. IL-33 stimulates Th2 cytokines and is highly expressed in airways of patients with asthma. Tanabe and colleagues examined the effect of IL-33 on CXCL8/IL-8 secretion from goblet or normally differentiated human bronchial epithelial (NHBE) cells and signaling pathways associated with IL-33 activation in these cells (34). CXCL8/IL-8 secretion into the apical side of the goblet cells was greater than that from normally differentiated cells, and IL33 stimulated apical CXCL8/IL-8 release from goblet cells, but not from normally differentiated cells. IL-33 increased ERK 1/2 phosphorylation in goblet cells. IL-13 induced ST2 mRNA and membrane-bound ST2 protein expression on the apical side surface of goblet cells when compared with normally differentiated cells. These results suggest a mechanism for enhanced airway inflammation in the asthmatic airway with goblet cell metaplasia.

Mouse models of atopic march suggest that systemic, skin-derived TSLP mediates progression from eczema to asthma (35). A prospective analysis of the relationship between plasma levels of TSLP to allergic sensitization and recurrent wheezing was conducted in the birth cohort from the Urban Environment and Childhood Asthma (URECA) study (36). Plasma TSLP levels were measured at 1, 2, and 3 years of age and analyzed for correlation with clinical parameters in each 
of the 3 years. Overall, a consistently significant association was not found between TSLP and eczema or allergic sensitization. With regard to recurrent wheezing, children with detectable TSLP at 1 year of age were significantly less likely to experience recurrent wheezing by three years of age than were those with children without detectable TSLP, but this was seen only in children without aeroallergen sensitization at 3 years. These findings suggest a possible underlying distinction between the pathogenesis of developing atopic and that of non-atopic recurrent wheeze.

\subsection{Non-allergic mechanisms underlying asthma and rhinitis}

Asthma has almost universally been regarded as an atopic disease involving allergen exposure, allergic sensitization with a Th2 CD4+ lymphocyte response, and subsequent IL-5 mediated eosinophilic airways inflammation, resulting in enhanced bronchial reactivity and eventually in reversible airflow obstruction. However, there is now increasing evidence that other inflammatory mechanisms may be involved in producing the final common pathway of enhanced bronchial reactivity and reversible airflow obstruction that characterizes asthma. Elucidation of such mechanisms involved in the airway inflammation is important to permit their manipulation for therapeutic gain.

Cross-sectional and longitudinal studies show that obese adults have more asthma than do nonobese adults. A proposed mechanism is via effects of adipokines (leptin and adiponectin) on the 
immune system. Asthma levels were positively associated with serum leptin in the Global Asthma and Allergy Network of Excellence (GA $\left.{ }^{2} L E N\right)$ clinical follow-up survey (37). However, these associations were attenuated after adjustment for confounders and became non-significant after additional adjustment for obesity measures and multiple comparisons. Therefore, there is a possibility that this association is secondary to associations of both with obesity measures.

Histone acetyltransferases (HATs) and histone deacetylases (HDACs) regulate gene expression. Gunawardhana and colleagues investigated total HAT/HDAC activity and gene expression in isolated blood monocytes and sputum macrophages from healthy individuals $(n=9)$ and patients with asthma $(n=52)(38)$. There was a significant inverse association between blood monocyte HAT and HDAC activity. Neutrophilic asthma was associated with increased blood monocyte HAT enzyme activity, decreased HDAC activity and an increased HAT: HDAC ratio when compared with eosinophilic asthma, which demonstrated further systemic manifestations relating to the altered inflammatory gene transcription profile of neutrophilic asthma.

The toll-like receptors, TLR5 and TLR7, have recently been proposed to play a role in asthma immunopathogenesis. Advanced immunohistochemical mapping of TLR5 and TLR7 was performed on bronchial and transbronchial biopsies from healthy individuals and patients with moderate or severe asthma (39). Patients with severe asthma had decreased total and epithelial TLR5 expression when compared with the controls and the patients with moderate asthma. TLR7 
expression was found in several structural cells and asthma-related immune cells; TLR7

expression was also decreased in patients with severe asthma. Within the asthma groups, both TLR5 and TLR7 expression correlated with multiple lung function parameters. Hence, patients with severe asthma may suffer from insufficient TLR signaling during viral or bacterial infections leading to poor and impaired defense mechanisms.

Disintegrin and metalloproteinase domain 8 (ADAM8) is an enzyme expressed on most leukocytes and may be important for facilitating leukocyte migration in respiratory disease. Induced sputum was collected from 113 patients with asthma (severe $n=31$, uncontrolled $n=39$, and controlled $n$ = 35), 20 patients with COPD, and 21 healthy controls (40). ADAM8 mRNA and soluble ADAM8 protein levels were significantly higher in both the asthma and the COPD patients than in the healthy controls. ADAM8 mRNA and sADAM8 protein levels were significantly higher in patients with severe asthma than in those with controlled asthma. While the total inflammatory cell count and neutrophils were elevated in the sputum of the patients with severe asthma, ADAM8 expression was positively correlated with the sputum total cell count and sputum neutrophils. ADAM8 may facilitate neutrophil migration to the airways in severe asthma and COPD.

Mast cell-airway smooth muscle interactions also play a key role in the pathogenesis of asthma. Alkhouri and colleagues identified the factors expressed in non-asthmatic ASM that might inhibit MC chemotaxis (41). From an array of 120 cytokines, CXCL1 was the only factor expressed in 
abundance by Th1-stimulated non-asthmatic ASMs when compared with asthmatic ASMs. In vitro experiments identified CXCL1 as a negative regulator of MC chemotaxis. They also suggested that there is a defect in the CXCL1 axis in asthma that acts as a protective brake in normal ASM, and therefore, the increased $\mathrm{MC}$ accumulation in asthma is due at least in part to a failure of the inhibitory mechanism.

$\gamma \delta$ T cells have previously been shown to down-regulate acute inflammatory responses in the lung. Murdoch and colleagues studied the role of $\gamma \delta$ T cells in remodeling caused by chronic inflammatory responses in mice in a house dust mite model of asthma (42). They demonstrated that blockade of $\gamma \delta \mathrm{T}$ cells exacerbated the inflammatory response and led to a greater degree of remodeling changes.

Infiltration of fibrocytes (FCs) in the airway smooth muscle is a feature of asthma. Lin and colleagues explored whether FCs modulate the phenotype of airway smooth muscle cells (ASMCs) in asthmatic patients as compared with controls (43). Fibrocytes did not affect ASMC proliferation or expression of TGF- $\beta 1$, eotaxin, $\alpha-S M A$ and MLCK; however, ASMC production of IL- 8 and IL6 was increased in the co-culture and transwell culture by FCs. ASMC treated with fibrocyteconditioned medium were immunopositive for IL-8/IL-6 and produced more IL-8/IL-6. Furthermore, siRNA silencing of NF- $\mathrm{KB}-\mathrm{p} 65$ or ERK1/2 in transwell cultures of asthmatic ASMC 
with normal FCs decreased IL-8 and IL-6 production. These results demonstrate a pro-

inflammatory role for FCs and a possible mechanism of the inflammatory phenotype in asthma.

\subsection{Viruses and asthma exacerbations}

It is well established that viral upper respiratory tract infections (URIs), usually due to rhinovirus, are the most common triggers for asthma exacerbations in adults and children an area reviewed by Mackenzie et al (44). The reasons for this include the possibility of a defect in viral host defence at the level of the bronchial epithelium $(45,46)$. The assumption is that if this defect could be restored then asthmatic patients would be protected from viral-induced exacerbations.

Parsons and colleagues investigated the expression and function of pathogen recognition receptors on epithelial cells from healthy controls and asthmatic patients to determine the role they play in viral infections (47). They confirmed a previously reported defect in the generation of type 1 and type III interferon responses in asthmatic epithelial cells. However, this did not appear to be caused by differences in the expression of innate immune receptors, but by a defect in signalling.

A contrasting possibility has been raised that excessive virus-induced interferon production during acute infections can contribute to airway inflammation and exacerbations of asthma (48). In sputum samples, interferon gamma expression was significantly greater in patients with 
asthma exacerbations than in patients without exacerbations. IFN- $\gamma$ mRNA levels correlated with the peak Asthma Index. Additionally, IL-13, IL-10, and eosinophil major basic protein mRNA levels were higher in patients with asthma exacerbations than in patients without exacerbations, and IL-13 mRNA correlated with the peak Asthma Index. Therefore, asthma exacerbations are associated with increased rather than decreased expression of interferons early in the course of infection.

Rhinovirus and IgE act in concert to promote asthma exacerbations. Basophils are the principal cell type activated by IgE in the blood, and basophils in atopic asthmatic patients, but not in nonatopic controls, show up-regulated the TSLP receptors upon IgE receptor ligation (49). The magnitude of this response was correlated with the proportion of serum total IgE that was allergen-specific. Circulating basophils displayed increased IgE responsiveness three weeks after rhinovirus infection in patients with atopic asthma. This observation, coupled with increased expression of Syk, implicates basophils in promotion, or else prolongation, of rhinovirus-induced inflammation in patients with atopic asthma.

Lower respiratory tract symptoms, airflow obstruction and neutrophilic airway inflammation were increased in experimental RV-induced asthma exacerbations. Neutrophil-related CXC chemokines and anti-microbial peptides were increased and related to clinical, virological, and pathological outcomes in RV-induced exacerbations of asthma (50). Thus, RV infection in asthma 
may lead to increased release of CXCL8/IL-8, attracting neutrophils into the airways, where they release HNP 1-3, which in turn further enhances airway neutrophilia.

For reasons that are unclear, not all asthmatic patients have an exacerbation with an URTI.

Manthei and colleagues investigated whether the profile of cytokines released from the upper airway in response to natural viral infection could predict who would go on to develop an asthma exacerbation (51). From the large number of cytokines that they measured, they found that VEGF and TNF- $\alpha$ stood out as predicting the likelihood of an exacerbation. While it is possible that this information could be used as a test to predict exacerbations, at the least, it should offer some clues as to how viral infections cause exacerbations.

Respiratory syncytial virus (RSV) bronchiolitis leads to hospitalisation in 2-3\% of children in their first year of life. Approximately 40\% of previously healthy infants hospitalized for RSV bronchiolitis will later be diagnosed with asthma. Randolph et al found that vitamin D binding protein (VDBP) GC1s haplotype carriage was associated with hospitalisation for RSV bronchiolitis in infancy in two independent cohorts (52). The GC1s haplotype is associated with higher VDP levels, resulting in less freely available vitamin D. This study supports previous findings linking vitamin D deficiency to RSV susceptibility.

\subsection{Allergens}

Circulating levels of specific IgE are good markers of sensitization, but not of clinically symptomatic allergy. Michaud and colleagues quantified circulating IL-4- and IL-13-secreting T 
cells specific for HDM in children presenting with HDM-allergic asthma associated or not associated with rhinitis and correlated the results with the clinical symptoms (53). The number of HDM-specific IL-4- and IL-13-secreting T cells was higher in patients with allergic asthma than in those with non-allergic asthma. Although it varied with the season of blood sampling, with a peak in the fall and in the early spring, independently of the season, the number of HDM-specific IL-4-secreting T cells correlated with rhinitis severity. Allergen-specific IL-4- and IL-13producing T cells were detected only in HDM-allergic asthmatic children but not in patients with non-allergic asthma; thus, these cells are suitable markers to diagnose and monitor allergy and its severity and, therefore, correctly assign patients to specific immunotherapy regimens.

Molecular allergy diagnostics is a prerequisite for future component-resolved specific immunotherapy due to the high heterogeneity of sensitization profiles. Data is currently lacking on molecular allergy diagnostics in adults with grass pollen allergy with regard to conjunctival and nasal provocation tests outcomes and specific immunotherapy. Darsow and colleagues assessed whether molecular allergy diagnostics for grass pollen allergens could help with predicting provocation test outcomes and serve as a basis for future component-resolved specific immunotherapy (54). Sera of 101 adults with grass pollen allergy were analyzed for IgE against

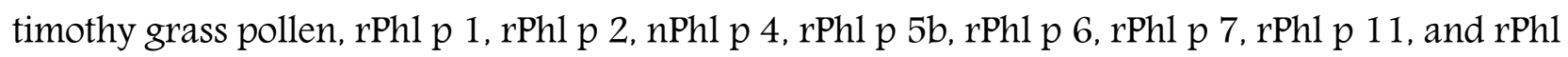
p12 and correlated with the individuals' outcome in the nasal and conjunctival provocation tests and investigated in regard to a potential component-resolved specific immunotherapy. Although 
an increasing number of sensitizations to timothy grass allergens was correlated to a positive reaction in the conjunctival and nasal provocation tests, in molecular sensitization profiles, a substantial heterogeneity was detected, with none of the patients exactly matching the allergen composition of a previously published component-resolved specific immunotherapy.

IgE-mediated AR to grass pollen can successfully be treated with either allergen immunotherapy tablets (SLIT tablet) or SQ-standardized subcutaneous immunotherapy (SCIT). The efficacies of these two treatment modalities for grass allergy are comparable, but the immunological mechanisms may differ. Aasbjerg and colleagues randomized 40 individuals with grass pollen rhinitis into groups receiving SCIT, SLIT tablet, or neither and followed them for 15 months with regular serum measurements of specific IgE, IgG4, IgE-blocking factor, facilitated antigen presentation and basophil activation test (55). Both SCIT and the SLIT tablets induced significant changes in specific IgE antibodies and competition assays. Overall, SCIT induced larger changes than did the SLIT tablets. The maximal changes were generally reached after 3 months' treatment. The data was discussed in an accompanying editorial and it was pointed out by Barbara Bohle that the differences could be due to the adjuvant used in SCIT or the higher amount of allergen delivered with this method although it is interesting in this context that the specific IgE response to SLIT was higher. She pointed out that the crucial question is how these immunological changes relate to clinically efficacy (56). With regards to assessing efficacy Calderon et al reviewed the literature to compare the different methods used to assess efficacy in clinical trials of SLIT for 
hayfever (57). They found a range of methodologies even when ostensibly measuring the same parameter such asdaily symptom score which they concluded makes comparing clinical trials very difficult. Greater standardization is required. Another important aspect of SLIT is the issue of adherence. Antico reviewed the evidence that adherence to SLIT is poor in real life settings although not in clinical trials. He suggested that this difference was due to the relative motivation of the patient and advocated a concordance based approach to treatment in which the patient becomes fully engaged in decision making (58).

Trees belonging to the order of Fagales show a distinct geographical distribution. While alder and birch are endemic to the temperate zones of the northern hemisphere, hazel, hornbeam, and oak prefer a warmer climate. However, specific immunotherapy for Fagales pollen-allergic patients is mainly performed using birch pollen extracts, thus limiting the success of this intervention in birch-free areas. Pichler and colleagues combined linear T cell epitope-containing stretches of the five most important Fagales allergens from birch, hazel, alder, oak, and hornbeam, resulting in a Fagales pollen hybrid (FPH) molecule applicable for SIT (59). The hybrid molecules showed a more efficient uptake and processing by DCs resulting in a modified T-cell response. The proteins had a lower IgE-binding capacity than did the parental allergens; thus, their high safety profile and increased efficacy emphasize their potential clinical application for the treatment of Fagales multi-sensitization. 


\subsection{Biological therapies}

An improved understanding of the pathobiological mechanisms of asthma and AR will provide a better insight into novel therapeutic targets. Biological therapies currently represent useful adjunctive treatments for asthma, especially in patients with more severe disease that is not responsive to conventional therapies alone.

Scheerens and colleagues described results from a study of the IL-13 blocking monoclonal antibody lebrikizumab (60). They studied 29 patients with mild atopic asthma treated with an asneeded bronchodilator therapy only in a multi-center, double-blind trial. A screening allergen challenge was performed to select patients with a LAR, who were then randomized to one of four doses of sub-cutaneous lebrikizumab or a placebo, given monthly over 12 weeks, after which a second allergen challenge was performed. The LAR was $48 \%$ less in patients treated with lebrikizumab than in the placebo-treated volunteers. There was also a trend for a reduction in maximal late declines in $\mathrm{FEV}_{1}$ in the lebrikizumab-treated patients when compared with those treated with the placebo. They also examined the effect of baseline expression of the biomarkers serum periostin, blood eosinophils, and FeNO to see whether these could be related to the effect of treatment on LAR. Results suggested that subjects with high Th2-markers at baseline tended to have a greater reduction in LAR after treatment with lebrikizumab than did those with low Th2markers. 
The CCR3 signaling pathway is one of the key regulatory pathways in eosinophil migration; eotaxin is a ligand for CCR3 and reflects eosinophilic airway inflammation. Neighbor and colleagues reported the results of the first clinical trial of an oral small molecule CCR3 antagonist (GW766994) on sputum eosinophil counts in patients with eosinophilic asthma (61). In a doubleblind parallel group study, 60 patients with asthma were randomized to $300 \mathrm{mg}$ of the CCR3 antagonist GW766994 twice daily or to a matching placebo for ten days followed by prednisone $30 \mathrm{mg}$ daily for five days. The main finding of that trial was that the CCR3 antagonist did not significantly reduce eosinophils or eosinophil progenitor cells in the sputum or blood of asthmatic patients receiving inhaled corticosteroids. The CCR3 antagonist had no beneficial effect on $\mathrm{FEV}_{1}$ although there was a small improvement in PC20 methacholine and ACQ scores.

The OX40/OX40L interaction contributes to an optimal T-cell response following allergic stimuli and plays an important role in the maintenance and reactivation of memory T effector cells. Gauvreau and colleagues tested whether treatment with an anti-OX4OL monoclonal antibody $(\mathrm{MAb})$ would inhibit allergen-induced responses in patients with asthma (62). Twenty-eight mild, atopic asthmatic patients were recruited for a double-blind, randomized, placebo-controlled, parallel-group trial to compare blockade of OX4OL using a humanized anti-OX4OL MAb with placebo administered intravenously in 4 doses over three months. Treatment with anti-OX4OL MAb did not attenuate the EAR or LAR at days 56 or 113 when compared with treatment with the placebo. In the anti-OX4OL MAb treatment group, total IgE was reduced $17 \%$ from pre-dosing 
levels, and sputum eosinophils were decreased by $75 \%$ by day 113 . However, there was no effect of anti-OX4OL MAb on AHR or blood eosinophils. It is possible that the treatment duration or antibody dose was insufficient to impact the airway responses.

SH2-containing inositol-5'-phosphatase 1 (SHIP1) is an endogenous inhibitor of the phosphoinositide-3-kinase pathway that is involved in the activation and chemotaxis of inflammatory cells. AQX-1125 is a first-in-class, oral SHIP1 activator with a novel antiinflammatory mode of action. Leaker and colleagues evaluated the effects of AQX-1125 on airway responses to allergen challenge in asthmatic patients (63). A randomized, double-blind, placebocontrolled, two-way crossover study was performed in 22 steroid-naïve, mild-to-moderate asthmatic patients with a documented late-phase response to inhaled allergens. AQX-1125 significantly attenuated the LAR when compared with the placebo and significantly increased the minimum $\mathrm{FEV}_{1}$ during LAR, although there was no effect on methacholine responsiveness or FeNO.

Prostaglandin D2 (PGD2) plays an important role in allergic inflammation. The PGD2 receptor, CRTH2, is expressed on basophils, eosinophils and Th2 lymphocytes and mediates chemotactic activity in allergic responses. Shiraishi and colleagues tried to define the role of CRTH2 in allergen-induced nasal responses in a mouse model of AR (64). A potent, selective CRTH2 receptor antagonist, ARRY-063, was administered in a mouse model of AR. Instillation of PGD2 in the nose 
of sensitized mice together with a low concentration of OVA induced both early- and late-phase reactions. Treatment with the CRTH2 receptor antagonist prevented the decreases in respiratory frequency seen immediately following the fourth challenge of sensitized mice. In the late-phase reaction, decreases in respiratory frequency and increases in nasal resistance were also prevented by antagonist treatment associated with reduced cytokine levels and inflammation in the nasal tissues. In addition, Diamant and colleagues investigated the tolerability and pharmacokinetics of setipiprant (ACT-129968), a selective, orally active CRTH2 antagonist, in allergic asthmatic patients and assessed the protective effects of multiple doses of this drug against allergen-induced airway responses (65). In this three-center, double-blind, placebo-controlled, crossover study, 18 allergic asthmatic males were randomized to setipiprant $1000 \mathrm{mg}$ or a matching placebo for five consecutive days. When compared with the placebo, setipiprant significantly reduced the allergen-induced late response, inhibiting the area under the response versus time curve by an average of $25.6 \%$ and significantly protected against the allergen-induced AHR to methacholine. These studies identified PGD2 as a mediator of both the early and late responses in AR and asthma and confirm that CRTH2 may be a promising target for the treatment of allergic disorders.

The peptide hormone relaxin plays a key role in the systemic hemodynamic and renovascular adaptive changes that occur during pregnancy, which is linked to its anti-remodeling effects. Intranasal administration of serelaxin was evaluated for its ability to reverse airway remodeling and AHR associated with asthma (66). Daily intranasal delivery of serelaxin significantly 
diminished epithelial thickening, epithelial pSmad2, subepithelial, and total lung collagen content and AHR. Thus, respirable preparations of serelaxin may have therapeutic potential for the prevention and/or reversal of established airway remodeling and AHR in asthma.

Studies in rodent asthma models demonstrated that intravenous mesenchymal stem cells (MSCs) attenuate the major pathological features of asthma including airway inflammation, AHR, and remodeling (67). Trzil and colleagues documented the effects of allogeneic, adipose-derived MSCs on airway inflammation, AHR and remodeling over time and investigated the mechanisms by which MSCs alter the local and systemic immunological responses in chronic experimental feline allergic asthma (68). Cats with chronic, experimentally induced asthma received six intravenous infusions of MSCs or placebo bimonthly at the time of study enrollment. There were no differences between the treatment groups or over time with respect to airway eosinophilia or AHR. However, significantly lower lung attenuation and bronchial wall thickening scores were noted in the CT images of the MSC-treated cats than in those of the placebo-treated cats at month 8 of the study.

Glucocorticoids are used to treat AR, but the mechanisms by which they induce disease remission

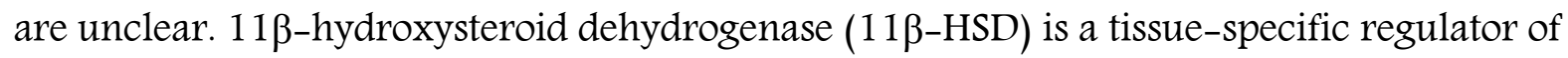
glucocorticoid responses, inducing the interconversion of inactive and active glucocorticoids. The expression levels of 11 $\beta-H S D 1$, CYP1 1B1, and cortisol were up-regulated in mild and 
moderate/severe persistent allergic nasal mucosa (69). In cultured epithelial cells treated with IL-

4, IL-5, IL-13, and IL-17A, 11 $\beta-$ HSD 1 expression and activity increased in parallel with the expression levels of CYP11B1 and cortisol. The siRNA technique or measurement of 11ß-HSD1 activity showed that the nasal epithelium converts cortisone to cortisol in an 11 $\beta$-HSD-dependent manner. These results indicate that the localized anti-inflammatory effects of glucocorticoids are regulated by inflammatory cytokines, which can modulate the expression of $11 \beta-H S D 1,11 \beta-$ HSD2, and CYP11B1, and by the intracellular concentrations of bioactive glucocorticoids.

\subsection{Smoking cessation, telemonitoring, and overtreatment}

Smoking has been shown to have several detrimental effects on asthma, including poor symptom control, attenuated treatment response, and accelerated decline in lung function. The aggravations of smoking on asthma may be caused by effects on airway inflammation, which has been found to be changed in asthmatic smokers. It is not known whether these smoking-induced airway inflammation changes are reversible after smoking cessation. Westergaard and colleagues assessed airway changes in asthmatic smokers before and during smoking cessation (70) . Fortysix smokers with asthma, all steroid-free, were recruited. All participants attempted smoking cessation over a period of three months. Twenty-six of the 46 patients succeeded in quitting smoking. In the quitters, improvements in methacholine AHR, ACQ6 score, and FeNO were observed, whereas no significant changes were found related to eosinophils or lung function. A 
small but significant decrease in neutrophils was present in quitters when compared with nonquitters.

Adherence to controller therapy in allergic diseases is low. Telemonitoring has been proposed to improve adherence to treatment in chronic diseases. Pizzulli and colleagues tested whether Internet-based telemonitoring during the grass-pollen season of children with allergic rhinoconjunctivitis might enhance adherence to treatment (71). Children and adolescents with moderate-to-severe seasonal allergic rhinoconjunctivitis to grass pollen requiring daily administration of nasal corticosteroids (NCS) were recruited. Participants were randomized to Internet-based monitoring system (AllergyMonitor ${ }^{\mathrm{TM}}$, AM, Technology Projects \& Software, Rome, Italy) or to usual care. The use of NCS, expressed as both the optimal adherence rate and average daily use, was higher in the AM group $(n=31)$ than in the control group $(n=32)$. Importantly, disease knowledge improved among the patients using AM but not among the controls.

Although AHR is a defining feature of asthma pathophysiology, bronchial challenge testing is not routinely used in primary care asthma management. Using both a direct (methacholine) and an indirect (inhaled mannitol) inhalational challenge, Manoharan and colleagues reported that 30\% of subjects were negative to both mannitol and methacholine AHR testing from an observational cross-sectional survey on apparently representative UK adults diagnosed and treated for asthma in the community (72). Those testing negative were older, had less atopy, better lung function, and 
less airway inflammation, with the majority being within normal limits for all these measures. The authors suggested the need for supervised step-down in those patients.

\subsection{Clinical Mechanisms}

\section{$\underline{2.1 \text { Regulation of T cell-responses }}$}

The cellular origin of the exaggerated IL-13 response seen in eosinophilic esophagitis (EoE) is not entirely clear. Peripheral blood cells and esophageal biopsies from children with EoE were investigated by Jyonouchi et al for their invariant NKT (iNKT) cell content and function (73). Children with EoE had fewer peripheral iNKTcells but a higher expression of these cells in esophageal biopsies. The circulating iNKT cells from EoE children showed a stronger Th2signature, being more positive for IL-4 and IL-13. Notably, iNKT cells from children with active EoE were significantly more positive for IL-13 than iNKT cells from children with a controlled EoE following exposure to cow's milk sphingomyelin. The authors conclude that sphingolipids in milk might drive a Th2 response and support eosinophil mediated inflammation partly through the activation of iNKT cells.

\subsection{Mast cell and basophil regulation}

The human Fc receptor

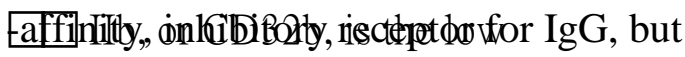

CD32b engagement has also been demonstrated to affect release of mediators from human basophils following IgE mediated activation. In a study by MacGlashan and co-workers, the regulation of IgE mediated signalling by CD32b was investigated in basophils (74). Basal CD32b 
expression in basophils varied to a high degree between individuals, and the expression was strongly influenced by IL-3. This observed profound variability in expression of CD32b had implications for inhibition of IgE induced release of active basophil mediators.

FceRI $\alpha$, FceRI $\beta$ and FceR $\gamma$ together form the high-affinity IgE receptor (FceRI). The localization of both the $\alpha$ and $\beta$ chains in giant papillae from patients with keratoconjunctivitis and in cultured human mast cells was determined by confocal microscopy by Okayama et al (75).

FceRI $\square \square \square \square \square$ detected both the cytoplasm and in the cell membrane. In a model system where FceRI $\beta$ was transduced into peripherally derived mast cells, there was an up-regulation of FceRI $\alpha$, FceRI $\beta$ and FceR $\gamma \square$ in the membrane as well as in the cytoplasm. However, the transduction of FceRI $\beta$ into the mast cell cytoplasm caused a dampening of Fc\&RI mediated effects such as degranulation, prostaglandin synthesis, $\mathrm{Ca}^{2+}$ influx and cytokine production, suggesting that cytoplasmic FcعRI $\beta \square$ at least in high concentrations, may act as a negative egulator of mast cell activation.

Ceramide, a sphingomyelin metabolite, is suggested to induce apoptosis in mast cells and to inhibit their release of active mediators. Mast cells from the bone marrow or peritoneal cavity were isolated from mice lacking acid sphingomyelinase (Asm), an enzyme implicated in the production of ceramide from sphingomyelin (76). Yang et al could then demonstrate that Asm regulates several different key steps in mast cell activation, as reduced mast cell $\mathrm{Ca}^{2+}$ signalling, degranulation and migration was observed in mast cells lacking Asm. Of note, the Asm deficient mice also displayed a less severe anaphylactic reaction in vivo. The results presented in this study points towards a mast cell regulatory role for Asm in vivo and highlights ceramide as a possible candidate to consider for therapeutic intervention.

\section{$\underline{2.3 \text { Immune tolerance }}$}


Strömbeck and collaborators investigated the relation between $\mathrm{CD}^{+} \mathrm{T}$ cell subsets the first days of life and the development of IgE-sensitization and allergy during infancy and early childhood (77). While early IgE-sensitisation correlated with a higher proportion of FOXP3 ${ }^{+} \mathrm{CD}_{2} 5^{\text {hi }} \mathrm{T}$ cells at birth and at 3 days of life, this association could not be observed for allergy. Furthermore, a farming environment was associated with lower proportions of FOXP3 ${ }^{+} \mathrm{CD} 25^{\text {hi }} \mathrm{T}$ cells at some, but not all, time points investigated during early life. The results show that the relationship between proportions of $\mathrm{FOXP}^{+} \mathrm{CD} 25^{\text {hi }} \mathrm{T}$ cells, $i$ e putative Tregs, and allergy is complex, and indicate that a high proportion of these cells at birth is not protective against future allergy development.

Hydrolysis is a way to reduce allergenicity of milk proteins and is used in production of hypoallergenic formulae. Meulenbroek and co-workers investigated how the degree of whey hydrolysis influenced T cell responses and basophil activity in vitro in cow's milk allergic (CMA) patients (78). A longer hydrolysis time reduced IgE recognition of proteins and peptides in the hydrolysate. T cell responses as well as basophil activation was also reduced with increased hydrolysis time, but not in all patients. In some individuals the basophil activity actually increased with increasing hydrolysis, possibly due to the reaction to degradation products. These results underscore the importance of not only considering the hydrolysis grade in hypoallergenic formulas, but to also evaluate how the hydrolysate influences immune cells and responses.

Maternal avoidance diets to prevent food allergies in their children are debated. Järvinen et al investigated the correlations between maternal avoidance of cow's milk during breast-feeding, breast milk levels of IgA to different cow's milk proteins and the development of CMA in the offspring (79). There were lower levels of IgA to certain milk protein in breast milk from mothers avoiding cow's milk, while their children had lower serum IgA, IgG 1 and IgG 4 responses to some components. Notably, lower IgG 4 and IgA to cow’s milk proteins were positively associated with 
CMA, showing that in this study maternal avoidance of cow's milk during breast-feeding was not protective against infant CMA. The authors conclude that reduced levels breast milk IgA with specificity for food antigens might lead to a deregulated food antigen uptake in the gut and increase the risk for food allergy in the children. Furthermore, maternal dietary restrictions may impair development of neonatal oral tolerance.

\subsection{Prediction of clinical reactivity}

While skin prick testing (SPT) is often the first method used for screening of possible causative agents in subjects with symptoms suggesting allergy, incorrect interpretation of positive SPT can result in overdiagnosis of allergic disorders and medicalization. In the European-wide Global Allergy and Asthma European Network (GA²LEN) SPT study, the relationship between SPT wheal size and patient-reported clinical relevance was investigated in 3068 patients for 18 inhalant allergens, using standardised procedures (80). The risk of allergic symptoms increased significantly with larger wheal sizes for 17 of the 18 allergens tested (all but Aspergillus fumigatus). As expected, positive SPTs correlated particularly well with physician-diagnosed allergic rhinitis, while the correlation was poorer for asthma and poorest for atopic dermatitis and food allergy. Children with positive SPT reactions had a smaller risk of sensitizations being clinically relevant than adults. The $80 \%$ positive predictive value for being clinically relevant varied from 3 to $10 \mathrm{~mm}$, depending on the allergen. The network provides a SPT form with the standard allergens including mm decision points for each allergen for clinical use.

Diagnostic algorithms, including e $g$ symptoms at first exposure, age, sex, SPT and circulating IgE to food allergens, have been proposed to predict outcome at food challenge (81). Preece et al assessed the value of fraction of exhaled nitric oxide (FeNO) in further improving prediction of a clinical allergic reaction in 53 children, with a mean peanut SPT wheal diameter between 3.0 and 
$8.9 \mathrm{~mm}$, undergoing an open-labelled peanut food challenge (OFC) (82). The authors propose that FeNO measurements should be included as a safe non-invasive step in a novel algorithm, prior to blood collection for analysis of circulating IgE to Ara h 2, to improve diagnostic accuracy, potentially decreasing the need for food challenge testing in the paediatric peanut-allergic population. The findings need to be confirmed in larger cohorts before any firm conclusion can be drawn on utility for clinical practice, however.

\section{$\underline{2.5 \text { Treatment models }}$}

A prophylactic multivalent allergen vaccine strategy was investigated in a murine model by Waeckerle-Men et al (83). Immunization with allergy vaccines containing aluminium hydroxide and CpG oligodeoxynucleotide as adjuvants protected in a Th1 and Treg dependent manner against later sensitization and anaphylaxis, both after juvenile and neonatal vaccination. Furthermore, monovalent and pentavalent (containing ovalbumin, cat, bee venom phospholipase $\mathrm{A}_{2}$, birch, house dust mite allergens) vaccines were protective to a similar level, suggesting a potential strategy to prevent allergy development towards several allergens.

Epicutaneous immunotherapy (EPIT) may shorten treatment duration by delivering the allergen to a site with a high number of antigen presenting cells, while reducing side effects by minimising allergen penetration to the vasculature. Dioszeghy and co-workers demonstrated that EPIT induces long term tolerance in peanut-sensitized mice, with efficient Tregs persisting during a long period of time after treatment cessation (84). Depleting Tregs using anti-CD25 antibody injection abolished the inhibitory action of EPIT on circulating IgE to peanut, Th2 responses and peanutinduced oesophagus injuries. Furthermore, Tregs transferred both immediately after EPIT and 8 weeks later were equally effective at preventing the allergic responses. The sustained tolerance suggests EPIT as a promising strategy for treatment of food allergies. 
Vaccines consisting of allergen-derived peptides lacking IgE reactivity and allergen-specific T cell epitopes bound to allergen unrelated carrier molecules that can induce blocking antibodies to the allergen may represent a novel strategy to improve safety during allergen specific immunotherapy. Linhart et al demonstrated that prophylactic as well as therapeutic vaccination with carrier bound Bet v 1 peptides lacking allergen-specific T cell epitopes reduced $\mathrm{T}$ cell responses to Bet $\mathrm{v} 1$ and allergic lung inflammation via blocking antibodies in a murine model for birch pollen allergy (85). The blocking antibodies were suggested to capture the antigen during sensitisation in the prophylactic setting and to inhibit IgE-facilitated antigen-presentation to the T cells when used therapeutically.

\subsection{The microbiome}

A reduced microbial exposure may underlie the increase in allergic diseases in affluent countries, with the gut microbiota representing the quantitatively most important source of microbial stimulation. Probiotic supplementation has been evaluated as an allergy preventive strategy in several studies, with combined pre- and postnatal supplementation showing promising eczema preventive effects (86). In one of the double-blind, randomised, placebo-controlled trials with preand postnatal supplementation, two different probiotic strains were compared, demonstrating that Lactobacillus rhamnosus HN001 (HN001) prevented eczema in children through to six years of age, while Bifidobacterium animalis subsp lactis HN019 (HN019) had no effect (87). Morgan et al then extended these findings by analysing whether these probiotic interventions could modify genetic predisposition to eczema conferred by 26 different susceptibility polymorphisms (88). HN001 supplementation protected children carrying a genetic variant putting them at a high risk of developing eczema, while HN019 conferred modest protection against the effects of some SNPs. Interestingly, HN001 supplementation also modified genetic susceptibility to eczema severity and 
atopy risk. Further research is required to elucidate the mechanisms of probiotic benefits in eczema prevention and the interaction between the maternal and offspring microbiome, genotype and immunity.

Probiotic interventions have so far failed to prevent respiratory allergy development. Furthermore, studies demonstrating that the gut microbiota differs in composition and diversity in children developing allergy have mostly performed the clinical follow-ups in infancy, with eczema as the primary outcome (86). As noted above Abrahamsson et al demonstrated that a low total diversity of the gut microbiota during the first month of life was associated with asthma but not allergic rhinoconjunctivitis in children at seven years of age (13). Speculatively, as viral lower respiratory tract infections are particularly linked to asthma development among atopic children, a reduced mucosal barrier function could be a consequence of a less diverse microbial stimulation. This may be linked to increased viral infection susceptibility, amplification of Th2 responses, and subsequent asthma development.

Staphylococcus aureus may play a role in the initiation and chronification of the skin inflammation in atopic dermatitis. Mechanisms underlying the increased $S$ aureus colonisation in atopic dermatitis were investigated by van Drongelen et al, using a keratinocyte cell line based epidermal model (89). Filaggrin knockdown and IL-31 supplementation resulted in significantly increased epidermal $S$ aureus colonisation. Furthermore, IL-31, but not filaggrin knockdown, prevented $S$ aureus induced expression of antimicrobial peptides, thus reducing protective responses.

Minai-Fleminger et al demonstrated that the $S$ aureus derived exotoxins Staphylococcal enterotoxin B (SEB), protein A and peptidoglycan enhanced activation of both human and mouse eosinophils (90). The activation was dependent on the glycosylphosphatidylinositol-anchored receptor CD48, possibly representing a novel therapeutic target for atopic dermatitis. 


\subsection{Epidemiology}

The role of breast-feeding in the prevention of allergic disease remains a topic of considerable interest and importance to both readers of the journal and their patients. However the message from the literature remains inconsistent (91-93). Taking an epidemiological approach the investigators in the PASTURE cohort study investigated whether the varying conclusions from different studies could be influenced by the composition of breast milk and in particular the levels of secretory IgA (sIgA), a relatively neglected antibody in allergic disease. Laura Orivuori and colleagues found a convincing inverse relationship between the concentrations of sIgA and the risk of developing eczema, although not asthma or atopy (94). Interestingly concentrations of sIgA were related to exposure to farm animals and cats which have also been shown to have a protective effect against allergic disease. There was no evidence for a role of TGF- $\square$ 1, another constituent of breast milk that has been proposed to influence allergic outcomes.

We first reported in this journal in 2009 the possibility that ingestion of acid suppression medication during pregnancy was associated with an increased risk of developing childhood asthma an association that was subsequently confirmed (95). Mulder extended this observation using prescribing data on 33,536 children as markers of allergic disease (96). They found that ingestion of both proton pump inhibitors and histamine receptor 2 blockers in pregnancy were associated not just with asthma, but with eczema and rhinitis. Most strikingly the risk factor for developing all three allergic diseases was 5 fold greater in those children whose mothers had ingested these drugs. This association now needs to be confirmed in a prospective study and potential mechanisms addressed.

Air quality as a causal and exacerbation factor in asthma and rhinitis receives considerable attention although much of this is focused on gaseous pollutants. At least as important are bio-aerosols and the indoor environment. Sharpe and colleagues reviewed the factors controlling levels of fungal 
allergens in buildings and the potential health effects concluding that if the will were there much could be done to improve the housing stock to reduce fungal allergen exposure (97).

The ying-yang of Th2 and Th1 mediated immune development is the basis for the school of thought that adheres to the hygiene hypothesis as the reason for the post-war epidemic of allergic disease. Support for this idea is provided by cross-sectional epidemiological evidence suggesting that childhood infection with $H$. pylori, the bacteria associated with peptic ulceration, protects against asthma. Amberbir and colleagues provided additional support for this concept in a longitudinal study in Ethiopia where they demonstrated in young children that infection with H. pylori, which was common, reduced the risk of both IgE sensitization and eczema (98).

There has been an interest in the relationship between infection with helminthic parasites and the presence of allergic disease for many decades to the extent that deliberate infection with helminths has been proposed as a treatment for allergy (99). The general hypothesis is that the strongly positive Th2 response engendered by helminthic parasitic infection prevents the development of allergic disease. Obeng and colleagues undertook an epidemiological study in Ghana looking at the association between infection with Schistosomiasis, allergic disease and socioeconomic status (100). A mixed picture emerged with a clear reduction in the risk of skin prick test reactivity to house dust mite in patients with evidence of helminthic infection, but no relationship with wheeze or asthma. Interestingly the overall rate of skin test positivity was highest in children from rural areas whereas the urban children from low socioeconomic class were at reduced risk of developing wheeze and asthma.

One of the more interesting observations to emerge in recent years has been the awareness of the syndrome of allergic disease to meat caused by sensitization to the alpha-gal carbohydrate epitope which is present in non-primate (except new world monkeys) mammals. A close link between 
sensitization and tick bites has been reported in the USA and Australia. Gonzales-Quintela investigated the prevalence of sensitization in two European populations from Spain and Denmark (101) . They found an overall rates of about $2 \%$ taking a cut off of $>0.35 \mathrm{KU}_{\mathrm{A}} / \mathrm{L}$ with the presence of alpha-gal sIgE antibodies associated with a history of tick bites, atopy and cat ownership.

Anaphylaxis is a fearful event and the risk of a severe attack is difficult to judge. Vetander et al investigated presentations to the emergency department to try and determine if the severity of the first episode of anaphylaxis could predict the severity of later events (102). They concluded that no such link could be made demonstrating the importance of managing any evidence of type 1 mediated allergic disease with the upmost caution and diligence.

The state of atopy, defined as the propensity to develop IgE antibodies against common environmental allergens, represent a profound statement about an individuals immune responsiveness. It might therefore be expected to be a marker for a general response to disease and therefore be related to the risk of mortality from certain conditions. Skaaby investigated this possibility in nearly 15,000 individuals from Denmark but found no clear signals between atopy and either a lower or higher risk of mortality (103) .

Eosinophil cationic protein is a biomarker of eosinophilic inflammation which can be readily measured in peripheral blood. Elmose and colleagues asked the question to what extent is the ECP level in serum controlled by genetic factors by investigating concentrations in 575 twins at least one of whom had self-reported asthma (104). About 50\% of the variance was explained by genetic factors with sex, BMI and airway responsiveness (AR), significantly associated. However this was a weak association explaining only $6 \%$ of the variance. Interestingly the genetic variance for AR and ECP was not shared consistent with the hypothesis that inflammation and smooth muscle dysfunction in asthma are to a large degree independent pathophysiological abnormalities(105). 


\subsection{Clinical Allergy}

\section{$\underline{4.1 \text { Anaphylaxis }}$}

Systemic mastocytosis (SM) is a rare but important condition that pre-disposes to anaphylaxis.

Gulen et al described their experience of 84 patients diagnosed with SM in the Mastocytosis Centre in Karolinska hospital in Sweden (106). 43\% of patients had suffered from at least one episode of anaphylaxis, mainly to venom, but with a significant number having idiopathic anaphylaxis. The clinical course of the reactions were severe with frequent occurrence of syncope. Males more frequently presented with anaphylaxis as did those with atopy. In a follow up paper later in the year this group investigated a group of thirty patients with unexplained anaphylaxis and found that $47 \%$ had evidence of an abnormal clonal mast cell population (107). They all had a baseline serum tryptase of greater than $11.4 \mathrm{ng} / \mathrm{ml}$. The authors emphasise the importance of looking for clonal mast cell disorders in patients with a raised tryptase and episodes of syncope. The topic of anaphylaxis in the context of mastocytosis was comprehensively reviewed by Peter Valent (108).

With reference to immunotherapy for venom induced anaphylaxis two groups reported on their experience focussing on biomarkers of effectiveness based on a sting challenge at the end of treatment. Out of 1532 patients $6.5 \%$ had objective adverse reactions to sting challenge. Worse outcome was associated with skin mastocytosis (6.4\% of patients), ACE inhibitor medication, honeybee venom allergy and reactions during treatment (109). Whether ACE inhibitor drugs were directly responsible or were a biomarker for significant cardiovascular disease which predisposed to treatment failure could not be addressed in this study. Stoevesandt et al reported on 775 consecutive cycles of venom immunotherapy with a focus on whether being on ACE inhibitors or beta blockers increased the risk of adverse events (110). No such association was found in this cohort where there was on overall rate of adverse events of $11.7 \%$ with $3 \%$ of the them rated as anaphylaxis. They did not address whether ACE inhibitors impacted on efficacy. In an accompanying editorial Slade and Douglass concluded that there was little evidence that ACE 
inhibitors per se were a risk factor for severe reactions during venom immunotherapy but that patients with significant cardiovascular disease could be at increased risk of treatment failure and may need a longer course of treatment (111).

Anaphylaxis in another setting, during general anaesthesia was investigated by Berroa et al (112). They did a detailed immunological work up on 37 patients referred with allergic type reactions during a general anaesthetic. They were particularly interested in the value of serum tryptase and plasma histamine as biomarkers. They found that a raised plasma histamine was a sensitive marker of an allergic type event but did not distinguish between IgE mediated reactions (19 subjects) and non-IgE mediated. A doubling of the baseline serum tryptase was the best criterion for distinguishing between these two types of reaction consistent with the published literature on the topic.

\section{$\underline{4.2 \text { Food allergy }}$}

Oral immunotherapy (OIT) for food allergy is a topical subject. It can clearly work but is associated with potentially severe side effects. Markers of risk of an unacceptable level of side effects would be useful in guiding management. Vazquez-Ortiz described their experience of OIT for egg allergy in 50 children aged 5-18 (113). Perhaps predictably they found that those with more severe symptoms and asthma at presentation were more likely to have adverse events than those with milder disease. However they found that a cut off value of $8.85 \mathrm{kU} / \mathrm{L}$ for specific IgE to egg was helpful in distinguishing those who would do well with egg OIT and those in whom it was poorly tolerated. This group also investigated the value of various biomarkers in predicting the development of natural tolerance in egg allergic children. They found that the best biomarker to predict tolerance was the sIgE/sIgG4 ratio to ovalbumin (114). Further discussion about the value of using more component resolved diagnostics to improve risk stratification for egg allergy was stimulated by correspondence from Dr Ciprandi’s group $(115,116)$. 
This year saw the publication of the BSACI guidelines on cow's milk allergy (117). They recognised both IgE and non-IgE mediated allergy and noted a prevalence of up to $7.5 \%$ of infants with onset being rare after 12 months and likely to resolve by adulthood. They pointed out that allergy in adulthood was usually a new diagnosis and often associated with anaphylaxis. The importance of excluding lactose intolerance was emphasised. They noted that a wheal size in skin prick tests to cows milk of $>4 \mathrm{~mm}$ was strongly predictive of cows milk allergy. They emphasised that management was based on avoidance with attempts at reintroduction as the child gets older. Oral tolerance induction was discussed as a promising new treatment in recaltriant cases. Guidelines often don't have as much impact as the specialist community might wish. It was therefore heartening that clear guidelines on the use of the measles, mumps and rubella vaccine (MMR) in egg allergic children had resulted in a reversal of the low uptake in this to the extent that it now matches or exceeds the non-allergic population (118).

Diagnosing IgE mediated food allergy can be difficult because of the variety of symptoms associated with this condition, the anxiety it induces and the high rate of IgE sensitisation without clinically meaningful reactions in many people. The double blind placebo controlled food challenge (DBPCFC) is regarded as the gold standard for research although in clinical practice the time consuming nature of the procedure limits its use. Ahrens et al examined their experience with DBPCFC focussing in the response to placebo (119). In 740 placebo challenges they observed a low rate of adverse reactions (2.8\%) with a slightly higher rate in children $<1.5$ years $(4.0 \%)$ than older children (1.5\%). The most common symptom reported was an increase in atopic dermatitis. This data demonstrates the robustness of the procedure and emphasises that it can be used even in infants. 
Pollen food syndrome (PFS) or oral allergy syndrome (OAS) in which allergic symptoms restricted to the oro-pharynx to a range of foods is due to cross-sensitisation from related pollen allergens is common. The most frequent link is with birch pollen allergy and with allergen families such as profilins which are labile and therefore degraded by heat and gastric acid. Although the presentation is very characteristic it can be difficult in some cases to distinguish between relatively benign crossreactivity to labile proteins versus less benign cross-reactivity with stable proteins such as lipid transfer proteins or primary sensitisation not related to pollen allergy which can result in severe anaphylaxis. Masthoff et al focussed on the diagnosis of hazelnut allergy in relation to OAS. Their main finding was that in the great majority of adults with symptoms on eating hazelnuts were due to cross-sensitisation with birch pollen in children it was much more likely to be due to primary sensitisation (120). However as pointed out by Turner and Campbell in an accompanying editorial $22 \%$ of adults who had hazelnut allergy in association with birch pollen allergy had systemic symptoms suggesting that OAS is often not benign and has the potential to cause serious allergic disease (121).

Lastly an important and relatively new condition, due to both IgE and non-IgE mediated food allergy, which continues to attract considerable attention is eosinophilic oesophagitis. The latest ideas on the pathogenesis and management of this condition was reviewed by Epstein and Warner (122).

\section{$\underline{4.3 \text { Drug Allergy }}$}

Neuromuscular blocking agents are the commonest cause of perioperative anaphylaxis in Europe. Leysen et al undertook a retrospective review of 272 patients who they had investigated for general anaesthetic (GA) related anaphylaxis 100 of whom had undergone a subsequent GA. Their main conclusion was that skin prick testing and the basophil activation test had excellent negative predictive values and were superior to specific IgE testing which gave a number of false positives 
(123). The relative value of skin testing versus specific IgE measurements in the diagnosis of allergy to quaternary ammonium ions which are present in neuromuscular blocking drugs was the subject of an interesting and unresolved debate between this group and Dr Mertes in the correspondence section of the journal $(124,125)$.

Allergic reactions to illicit drugs are not unusual in clinical practice and not well reported in the literature due to difficulties in diagnosis. This interesting topic was comprehensively reviewed by Swerts et al (126).

Non IgE mediated reactions to beta lactams resulting in delayed onset skin reactions are common and difficult to diagnose. Trautmann et al investigated the sensitivity and specificity of the lymphocyte transformation test (LTT) in 37 patients presenting with delayed type hypersensitivity to amoxicillin (127). They found that the test was specific but too insensitive to be useful clinically compared to skin testing with provocation testing as the gold standard. Sensitivity could be improved by co-stimulating the T cells with anti CD3 and anti-CD28 but this resulted in a marked loss of specificity.

Adverse reactions to drugs including hypersensitivity reactions are complex and heterogenenous. In a novel take on this subject Perkins and colleagues in an opinion piece proposed that systems biology approaches should be used to offer new insights into pathogenesis and management in particular focussing on genetic links that could allow personalised approaches to diagnosis and prediction of risk (128).

\section{$\underline{4.4 \text { New treatments for allergic disease. }}$}

Omalizumab, a monoclonal antibody which binds IgE and prevents its binding to the high affinity IgE receptor has been a very successful treatment for severe asthma and more recently for chronic spontaneous urticaria. Novartis have now developed ligelizumab, a follow up biological with the 
same mode of action which has much greater affinity for IgE than omalizumab (129). In the first clinical report of this drug Arm et al described the findings of two pharmacokinetic studies involving just under 200 subjects. They found that the increased binding affinity translated into increased suppression of free IgE with increased and more prolonged suppression of skin prick test wheal responses. The drug was well tolerated.

Probiotics continue to attract considerable attention as a way to prevent allergic disease by creating a non-allergenic gut microbiota in the neonatal period. Gorissen et al reported follow up data at six years on a peri-natal probiotic study that had shown a beneficial effect on eczema at 2 years (130). That beneficial effect was lost at six years and there was no significant difference in the incidence of other allergic diseases between the placebo and intervention groups although the numbers of subjects who had allergic disease was relatively small.

\subsection{Allergens}

\section{$\underline{5.1 \text { Newly discovered allergens }}$}

A new fungal allergen from Schizophyllum commune, identified by Toyoyome and colleagues, will greatly assist in the diagnosis of allergic bronchopulmonary mycoses (ABPM) to this species (131) . Although ABPM is frequently attributed to the Aspergillus species, it is becoming increasingly apparent other species are important. In Japan, S. commune-induced ABPM is the most common but is difficult to diagnose due to a lack of reagents. Sch c 1 is a promising candidate antigen for the serodiagnosis of allergic disease to S. commune since it elicited IgE and IgG binding in most patient sera, but not in control sera. Sch c 1 had approximately 50\% amino acid sequence identity with glucoamylase homologues from other species, such as Aspergillus, and as expected from other allergens with this degree of homology, either no or limited IgE cross-reactivity was observed.

\section{$\underline{5.2 \text { Component resolved diagnosis and allergen detection }}$}


The diagnosis of wheat allergy is difficult as IgE sensitisation to whole wheat extract by SPT or immunoassay is relatively non specific, as reiterated by Makela et al. in their study of 108 children suspected of having wheat allergy (132). The investigators however showed that the diagnosis of clinically relevant wheat allergy was improved using microarray, where IgE recognition of over 5 allergenic components significantly increased the diagnostic accuracy compared to whole wheat. Alpha-amylase inhibitors (AAI) were the main components that differentiated children with immediate symptoms compared to those that didn’t react, particularly dimeric AAI. Unfortunately despite the improvement in diagnosis using component resolved methods over extracts, the specificity and sensitivity of the component resolved assay was not sufficient to be clinically useful. The authors discussed the possibility of including other as yet uncharacterised wheat allergens to improve the specificity of component resolved diagnosis. Until then oral wheat challenge will continue to be the only reliable diagnostic method.

The potential exposure of adolescent children to food allergens in mattresses was explored in a Norwegian study (133). The investigators measured fish, milk, egg and peanut allergens in mattress dust using a semi-quantitative dot blot method. The study found almost all mattresses had at least one allergen present. The detection of fish allergens were the most common, followed by peanut milk and egg and the proximity of the kitchen to the bedroom increased the likelihood of detection in mattresses. Given the amount of time children spend in the bedroom, the authors suggest mattresses could be an important source of exposure to food allergens.

\section{$\underline{5.3 \text { Allergen modification for improved immunotherapy }}$}

A number of articles in 2014 reflect the continued rise of recombinant technologies to modify allergens to improve specific immunotherapy. As discussed above Pichler et al. generated a Fagales pollen hybrid (FPH) using PCR-based recombination of low IgE-binding allergen epitopes (59). They also produced an unordered structural variant by in silico mutagenesis, FPH4. Both 
monomeric proteins were shown to have reduced IgE binding to Bet $\mathrm{v} 1$, and in a murine model prevented pollen extract-induced allergic lung inflammation. Of note the structural modification of FPH4 boosted the immunogenicity of the protein, induced a marked cross-reactive IgG response, and skewed the T cell response towards the Th1 phenotype (low IL-4/high IFN- $\square$ ). The uptake of both FPH and FPH4 by dendritic cells was also significantly enhanced compared to Bet v 1 alone. The development of the pollen hybrids that encompass T-cell epitopes from birch, hazel, alder, oak and hornbeam has great potential in specific immunotherapy (SIT) of multi-sensitized patients.

A similar approach to improve SIT and to reduce side effects has been applied to the major cat allergen Fel d 1 (134). Seven recombinant mosaic proteins were generated by reassembly of nonIgE-reactive peptides of Fel d 1 which contained the sequence elements for induction of allergenspecific blocking IgG antibodies and T- cell epitopes. Three of the constructs resulted in a reduction of IgE reactivity and basophil activation. The generation of polyclonal IgG antibody to the three hypoallergenic Fel d 1 proteins in vivo were further shown to inhibit IgE reactivity of cat-allergic sera to wild type recombinant Fel d 1 in competition assays. Although other hypoallergenic Fel d 1 variants have been produced previously, the new constructs outlined in this article were less allergenic based on their basophil activation assays.

Hazebrouck and colleagues sought to exploit the unusual observation of minimal IgE crossreactivity between goat and cow Easein allergens for the development of hypoallergenic variants (135). Goat milk allergy is often reported in the absence of cow milk allergy, as well as following successful oral immunotherapy with cow milk, even though the major goat and cow Ecasein allergens have an amino acid sequence identity of $91 \%$. Children who are only sensitised to goat milk generally have more severe symptoms and are older. Recombinant fusion proteins of goat and cow Ecasein were initially produced to identify goat-specific Elasein epitopes. Site-directed mutagenesis was then employed to produce constructs with decreased IgE reactivity to goat 
casein. Substitutions to five amino acids located in two domains produced constructs that were unable to trigger the degranulation of RBL-SX38 cells passively sensitized with IgE antibodies from goat-allergic children. The hypoallergenic variants may be useful avenues to explore for future SIT.

Chemical modification of allergens is also a fruitful avenue to produce hypoallergenic proteins, as demonstrated by van Hoffen et al (136). They used reduction and alkylation (RA) to disrupt disulphide bonds to linearize the conglutin major allergens Ara h 2 and Ara h 6, with or without glutaraldehyde (GA) treatment. The allergoids RA, and to a lesser extent RAGA, stimulated T-cell responses, but tended to have less antibody binding (IgE, IgG1 and IgG4), especially for RAGA. Basophil release assays also showed the allergoids had a 10 to 100 -fold reduction in their ability to activate basophils for most donors. Of interest, the effect of the chemical modification of conglutin was less pronounced for a subgroup of patients who had high peanut-specific IgG1, which already partially blocked reactivity to the native conglutin.

\subsection{Immune recognition of allergens}

All five papers published this year that investigated immune recognition of allergens were for pollen allergens, most with a focus on group 1 and group 5 allergens. An exception to this was the study of IgE antibody binding to a panel of 8 timothy grass pollen allergens (Phleum pratense) and the correlation of IgE binding in regard to conjunctival and nasal provocation test outcomes (54). The main finding was the number of Phl p allergen sensitizations was significantly higher in the provocation-positive group compared with provocation-negative patients. The allergen hierarchy of importance in decreasing order was Phl p 1, Phl p 5b, Phl p 4, Phl p 6, Phl p 2, Phl p 11, Phl p 12 and Phl p 7. This prevalence of IgE binding has been mirrored in other studies, although binding to Phl p 4 was higher than expected for their cohort of 101 adult subjects. The authors noted that although Phl p 4 is not included in a current experimental component-resolved specific 
immunotherapy (CRT) that contains Phl p 1, Phl p 2, Phl p 5a/b and Phl p 6, the CRT would still target over $50 \%$ of timothy grass IgE in over $95 \%$ of their cohort. However the high heterogeneity of IgE binding would suggest that component-resolved diagnosis prior to specific immunotherapy could still be of benefit.

The diversity of IgE binding that exists within allergens was explored for the group 5 timothy grass allergen using recombinant isoallergens, fragments, mutants and synthetic peptides of Phl p 5 and human monoclonal IgE antibodies from grass-allergic patients (137). They showed the Phl p 5.0101 isoallergen had at least four non-overlapping IgE binding epitopes and there was considerable cross-reactivity to group 5 allergens from other temperate grass species. The Phl p 5.0201 isoallergen had only two of these epitopes for comparison. The authors proposed that the highdensity recognition of Phl p 5 could be a general feature of many potent allergens. The same group used a similar approach to characterise monoclonal IgE antibody binding to the major grass allergen Bet $\mathrm{v}$ 1, including identifying the structure of binding for one construct using X-ray crystallography (138). They identified four Bet v 1-specific IgE binders that target two non-overlapping Bet v 1 epitopes and found a crucial amino acid that was essential for interaction with human IgE. In another study on Bet v 1, Asam et al. examined the intrinsic properties of this molecule(139). They examined the effect of Bet v 1 binding to the surrogate ligand sodium deoxycholate (DOC) and found that ligand binding stabilised the molecule and induced Th2 effector cells in an in vivo model. They also performed antibody epitope mapping with or without ligand by nuclear magnetic resonance (NMR) spectroscopy and identified three major IgE binding regions on Bet $\mathrm{v} 1$. The authors confirmed that the ligand binding property of Bet $\mathrm{v} 1$ contributes to the allergenicity of the protein.

In contrast to the IgE binding studies, Archila et al. examined T-cell cross-reactivity to timothy grass pollen allergens using dual tetramer staining(140). This article, which was nicely reviewed by Moingeon in the same edition (141), found T-cells with varying degrees of cross-reactive profiles 
could be detected. Poa p 1 97-116, Lol p 1 221-240, Lol p 5a 199-218, and Poa p 5a 199-218 were identified as minimally cross-reactive T-cell epitopes that had no cross-reactivity to Phl p 1 and Phl p 5a epitopes. The authors also verified that the minimally cross-reactive T-cell epitopes are present in Grass-pollen-allergic subjects by ex vivo tetramer staining assays. Their results suggest that not all Pooideae grass epitopes with sequence homology are cross-reactive and supports the use of a multiple allergen system for immunotherapy rather than a mono-allergen system.

\section{$\underline{5.5 \text { Reviews on allergens }}$}

The molecular characterization, detection and clinical relevance of walnut allergens was reviewed in the March edition of the CEA journal by Costa et al (142). The review provided an excellent overview of the characterization and clinical relevance of the common (Juglans regia) and black (Juglans nigra) walnut allergens. The allergens are divided into two superfamilies of proteins, namely the prolamin (2S albumin family: Jug r 1, Jug n 1; nsLTP family: Jug r 3) and the cupin (Vicilin family: Jug r 2, Jug n 2.; 11 S globulin family; Jug r 4) that are all classified as major allergens that can cause severe and systemic allergic reactions. A new allergen belonging to the profilin family of proteins (Jug r 5) was recently identified in walnut, but its clinical relevance is not known. An important characteristic of all the walnut allergens is their potential cross-reactivity with homologues of other food allergens. Typically cross-reactivity was only observed where the amino acid identity was greater than $70 \%$, similar to what is observed for aeroallergens.

Although walnut allergy is not highly prevalent (reported at $1.8 \%$ in the multicentre EuroPrevall study), there is the potential for a fatal anaphylactic reaction due to exposure in susceptible individuals. Total avoidance of walnuts is the only option at this stage since oral immunotherapy induced tolerance to walnut is not available, and there is no established clinical threshold level for walnut. The requirement for complete avoidance of walnut allergens has resulted in a number of methodologies to detect walnut contamination during commercial food production, either by protein 
or DNA methods. The review underlined that protein assays such as ELISA should be interpreted with caution as walnut allergens often cross-react with other nuts and plant foods. Mass

spectrometry and DNA-based methods for detection is more specific and could be beneficial but are not well developed. For example genosensors and microarrays are likely to be the DNA-based methods to progress forward as several targets can be multiplexed.

The review by Davies highlighted the contribution of subtropical grass pollens to allergic disease (143). In subtropical regions worldwide, the Chloridoideae (e.g. Cynodon dactylon; Bermuda grass) and Panicoideae (e.g. Paspalum notatum; Bahia grass) are the most abundant, and are more clinically relevant for patients in those regions. It summarised the marked differences between temperate (Pooideae, Phleum pratense; Timothy, or Lolium perenne; Ryegrass) grass pollens and subtropical pollens, and the subsequent sensitisation of patients. The most pertinent is the group 2 and 5 allergens, which are absent from subtropical pollens, and likewise several novel subtropical pollen allergens are not found in temperate grasses. The review provides a useful phylogenetic comparison between the grass families, and characterization of the subtropical pollen allergens that have been identified so far. It recommends the use of group 1 allergens for standardisation of subtropical grass extracts for immunotherapy and diagnosis.

1. Kurukulaaratchy RJ, Zhang H, Raza A, Patil V, Karmaus W, Ewart S, et al. The diversity of young adult wheeze: a cluster analysis in a longitudinal birth cohort. Clinical and experimental allergy : journal of the British Society for Allergy and Clinical Immunology. 2014;44(5):724-35.

2. Gonzalez M, Jegu J, Kopferschmitt MC, Donnay C, Hedelin G, Matzinger F, et al. Asthma among workers in healthcare settings: role of disinfection with quaternary ammonium 
compounds. Clinical and experimental allergy : journal of the British Society for Allergy and Clinical Immunology. 2014;44(3):393-406.

3. Molfino NA, Gossage D, Kolbeck R, Parker JM, Geba GP. Molecular and clinical rationale for therapeutic targeting of interleukin-5 and its receptor. Clin Exp Allergy. 2012;42(5):71237.

4. Zhang XY, Simpson JL, Powell H, Yang IA, Upham JW, Reynolds PN, et al. Full blood count parameters for the detection of asthma inflammatory phenotypes. Clinical and experimental allergy : journal of the British Society for Allergy and Clinical Immunology. 2014;44(9):1137-45.

5. Cianchetti S, Bacci E, Ruocco L, Pavia T, Bartoli ML, Cardini C, et al. Are sputum eosinophil cationic protein and eosinophils differently associated with clinical and functional findings of asthma? Clinical and experimental allergy : journal of the British Society for Allergy and Clinical Immunology. 2014;44(5):673-80.

6. Kupczyk M, ten Brinke A, Sterk PJ, Bel EH, Papi A, Chanez P, et al. Frequent exacerbators--a distinct phenotype of severe asthma. Clinical and experimental allergy : journal of the British Society for Allergy and Clinical Immunology. 2014;44(2):212-21.

7. Brandenberger C, Li N, Jackson-Humbles DN, Rockwell CE, Wagner JG, Harkema JR. Enhanced allergic airway disease in old mice is associated with a Th17 response. Clinical and experimental allergy : journal of the British Society for Allergy and Clinical Immunology. 2014;44(10):1282-92.

8. Birmingham JM, Gillespie VL, Srivastava K, Li XM, Busse PJ. Influenza A infection enhances antigen-induced airway inflammation and hyperresponsiveness in young but not aged mice. Clinical and experimental allergy : journal of the British Society for Allergy and Clinical Immunology. 2014;44(9):1188-99.

9. Bachert C, van Steen K, Zhang N, Holtappels G, Cattaert T, Maus B, et al. Specific IgE against Staphylococcus aureus enterotoxins: an independent risk factor for asthma. J Allergy Clin Immunol. 2012;130(2):376-81 e8.

10. Song WJ, Chang YS, Lim MK, Yun EH, Kim SH, Kang HR, et al. Staphylococcal enterotoxin sensitization in a community-based population: a potential role in adult-onset asthma. Clinical and experimental allergy : journal of the British Society for Allergy and Clinical Immunology. 2014;44(4):553-62.

11. Brooks C, Pearce N, Douwes J. The hygiene hypothesis in allergy and asthma: an update. Curr Opin Allergy Clin Immunol. 2013;13(1):70-7.

12. Abrahamsson TR, Jakobsson HE, Andersson AF, Bjorksten B, Engstrand L, Jenmalm MC. Low diversity of the gut microbiota in infants with atopic eczema. J Allergy Clin Immunol. 2012;129(2):434-40, 40 e1-2.

13. Abrahamsson TR, Jakobsson HE, Andersson AF, Bjorksten B, Engstrand L, Jenmalm MC. Low gut microbiota diversity in early infancy precedes asthma at school age. Clinical and experimental allergy : journal of the British Society for Allergy and Clinical Immunology. 2014;44(6):842-50.

14. Cheng G, Smith AM, Levin L, Epstein T, Ryan PH, LeMasters GK, et al. Duration of day care attendance during infancy predicts asthma at the age of seven: the Cincinnati Childhood Allergy and Air Pollution Study. Clinical and experimental allergy : journal of the British Society for Allergy and Clinical Immunology. 2014;44(10):1274-81.

15. Baba S, Kondo K, Toma-Hirano M, Kanaya K, Suzukawa K, Ushio M, et al. Local increase in IgE and class switch recombination to IgE in nasal polyps in chronic rhinosinusitis. Clinical and experimental allergy : journal of the British Society for Allergy and Clinical Immunology. 2014;44(5):701-12.

16. Cao PP, Zhang YN, Liao B, Ma J, Wang BF, Wang H, et al. Increased local IgE production induced by common aeroallergens and phenotypic alteration of mast cells in Chinese eosinophilic, but not non-eosinophilic, chronic rhinosinusitis with nasal polyps. Clinical and 
experimental allergy : journal of the British Society for Allergy and Clinical Immunology. 2014;44(5):690-700.

17. Buslau A, Voss S, Herrmann E, Schubert R, Zielen S, Schulze J. Can we predict allergeninduced asthma in patients with allergic rhinitis? Clinical and experimental allergy : journal of the British Society for Allergy and Clinical Immunology. 2014;44(12):1494-502.

18. Caillaud D, Horo K, Baiz N, Banerjee S, Charpin D, Lavaud F, et al. Exercise-induced bronchospasm related to different phenotypes of rhinitis without asthma in primary schoolchildren: the French Six Cities Study. Clinical and experimental allergy : journal of the British Society for Allergy and Clinical Immunology. 2014;44(6):858-66.

19. Ziyab AH, Karmaus W, Zhang H, Holloway JW, Steck SE, Ewart S, et al. Allergic sensitization and filaggrin variants predispose to the comorbidity of eczema, asthma, and rhinitis: results from the Isle of Wight birth cohort. Clinical and experimental allergy : journal of the British Society for Allergy and Clinical Immunology. 2014;44(9):1170-8.

20. Yatagai Y, Sakamoto T, Yamada H, Masuko H, Kaneko Y, Iijima H, et al. Genomewide association study identifies HAS2 as a novel susceptibility gene for adult asthma in a Japanese population. Clinical and experimental allergy : journal of the British Society for Allergy and Clinical Immunology. 2014;44(11):1327-34.

21. Hirota T, Takahashi A, Kubo M, Tsunoda T, Tomita K, Doi S, et al. Genome-wide association study identifies three new susceptibility loci for adult asthma in the Japanese population. Nat Genet. 2011;43(9):893-6.

22. Abdelmotelb AM, Rose-Zerilli MJ, Barton SJ, Holgate ST, Walls AF, Holloway JW. Alphatryptase gene variation is associated with levels of circulating IgE and lung function in asthma. Clinical and experimental allergy : journal of the British Society for Allergy and Clinical Immunology. 2014;44(6):822-30.

23. Harb H, Renz H. Update on epigenetics in allergic disease. J Allergy Clin Immunol. 2015;135(1):15-24.

24. Gaffin JM, Raby BA, Petty CR, Hoffman EB, Baccarelli AA, Gold DR, et al. beta-2 adrenergic receptor gene methylation is associated with decreased asthma severity in innercity schoolchildren: asthma and rhinitis. Clinical and experimental allergy : journal of the British Society for Allergy and Clinical Immunology. 2014;44(5):681-9.

25. Lajoie S, Lewkowich I, Herman NS, Sproles A, Pesce JT, Wynn TA, et al. IL-21 receptor signalling partially mediates Th2-mediated allergic airway responses. Clinical and experimental allergy : journal of the British Society for Allergy and Clinical Immunology. 2014;44(7):976-85.

26. Yao XJ, Huang KW, Li Y, Zhang Q, Wang JJ, Wang W, et al. Direct comparison of the dynamics of IL-25- and 'allergen'-induced airways inflammation, remodelling and hypersensitivity in a murine asthma model. Clinical and experimental allergy : journal of the British Society for Allergy and Clinical Immunology. 2014;44(5):765-77.

27. Dua B, Tang W, Watson R, Gauvreau G, O'Byrne PM. Myeloid dendritic cells type 2 after allergen inhalation in asthmatic subjects. Clinical and experimental allergy : journal of the British Society for Allergy and Clinical Immunology. 2014;44(7):921-9.

28. Botturi K, Lacoeuille Y, Cavailles A, Vervloet D, Magnan A. Differences in allergeninduced $\mathrm{T}$ cell activation between allergic asthma and rhinitis: Role of CD28, ICOS and CTLA-4. Respir Res. 2011;12:25.

29. Shen C, Hupin C, Froidure A, Detry B, Pilette C. Impaired ICOSL in human myeloid dendritic cells promotes Th2 responses in patients with allergic rhinitis and asthma. Clinical and experimental allergy : journal of the British Society for Allergy and Clinical Immunology. 2014;44(6):831-41.

30. Hui CC, Murphy DM, Neighbour H, Al-Sayegh M, O'Byrne S, Thong B, et al. T cellmediated induction of thymic stromal lymphopoietin in differentiated human primary 
bronchial epithelial cells. Clinical and experimental allergy : journal of the British Society for Allergy and Clinical Immunology. 2014;44(7):953-64.

31. Negoro T, Shimizu S, Narushima M, Banham AH, Wakabayashi H, Takayanagi R, et al. Elevated receptor for activated $\mathrm{C}$ kinase 1 expression is involved in intracellular Ca2+ influx and potentially associated with compromised regulatory $\mathrm{T}$ cell function in patients with asthma. Clinical and experimental allergy : journal of the British Society for Allergy and Clinical Immunology. 2014;44(9):1154-69.

32. van der Vlugt LE, Mlejnek E, Ozir-Fazalalikhan A, Janssen Bonas M, Dijksman TR, Labuda LA, et al. CD24(hi)CD27(+) B cells from patients with allergic asthma have impaired regulatory activity in response to lipopolysaccharide. Clinical and experimental allergy : journal of the British Society for Allergy and Clinical Immunology. 2014;44(4):517-28. 33. Mathias CB, Guernsey LA, Zammit D, Brammer C, Wu CA, Thrall RS, et al. Proinflammatory role of natural killer cells in the development of allergic airway disease. Clinical and experimental allergy : journal of the British Society for Allergy and Clinical Immunology. 2014;44(4):589-601.

34. Tanabe T, Shimokawaji T, Kanoh S, Rubin BK. IL-33 stimulates CXCL8/IL-8 secretion in goblet cells but not normally differentiated airway cells. Clinical and experimental allergy : journal of the British Society for Allergy and Clinical Immunology. 2014;44(4):540-52. 35. Jiang H, Hener P, Li J, Li M. Skin thymic stromal lymphopoietin promotes airway sensitization to inhalant house dust mites leading to allergic asthma in mice. Allergy. 2012;67(8):1078-82.

36. Demehri S, Yockey LJ, Visness CM, Jaffee KF, Turkoz A, Wood RA, et al. Circulating TSLP associates with decreased wheezing in non-atopic preschool children: data from the URECA birth cohort. Clinical and experimental allergy : journal of the British Society for Allergy and Clinical Immunology. 2014;44(6):851-7.

37. Newson RB, Jones M, Forsberg B, Janson C, Bossios A, Dahlen SE, et al. The association of asthma, nasal allergies, and positive skin prick tests with obesity, leptin, and adiponectin. Clinical and experimental allergy : journal of the British Society for Allergy and Clinical Immunology. 2014;44(2):250-60.

38. Gunawardhana LP, Gibson PG, Simpson JL, Powell H, Baines KJ. Activity and expression of histone acetylases and deacetylases in inflammatory phenotypes of asthma. Clinical and experimental allergy : journal of the British Society for Allergy and Clinical Immunology. 2014;44(1):47-57.

39. Shikhagaie MM, Andersson CK, Mori M, Kortekaas Krohn I, Bergqvist A, Dahl R, et al. Mapping of TLR5 and TLR7 in central and distal human airways and identification of reduced TLR expression in severe asthma. Clinical and experimental allergy : journal of the British Society for Allergy and Clinical Immunology. 2014;44(2):184-96.

40. Oreo KM, Gibson PG, Simpson JL, Wood LG, McDonald VM, Baines KJ. Sputum ADAM8 expression is increased in severe asthma and COPD. Clinical and experimental allergy : journal of the British Society for Allergy and Clinical Immunology. 2014;44(3):342-52.

41. Alkhouri H, Moir LM, Armour CL, Hughes JM. CXCL1 is a negative regulator of mast cell chemotaxis to airway smooth muscle cell products in vitro. Clinical and experimental allergy : journal of the British Society for Allergy and Clinical Immunology. 2014;44(3):381-92.

42. Murdoch JR, Gregory LG, Lloyd CM. gammadeltaT cells regulate chronic airway inflammation and development of airway remodelling. Clinical and experimental allergy : journal of the British Society for Allergy and Clinical Immunology. 2014;44(11):1386-98. 43. Lin TY, Venkatesan N, Nishioka M, Kyoh S, Al-Alwan L, Baglole CJ, et al. Monocytederived fibrocytes induce an inflammatory phenotype in airway smooth muscle cells. Clinical and experimental allergy : journal of the British Society for Allergy and Clinical Immunology. 2014;44(11):1347-60. 
44. Mackenzie KJ, Anderton SM, Schwarze J. Viral respiratory tract infections and asthma in early life: cause and effect? Clinical and experimental allergy : journal of the British Society for Allergy and Clinical Immunology. 2014;44(1):9-19.

45. Hansel TT, Johnston SL, Openshaw PJ. Microbes and mucosal immune responses in asthma. Lancet. 2013;381(9869):861-73.

46. Parker LC, Stokes CA, Sabroe I. Rhinoviral infection and asthma: the detection and management of rhinoviruses by airway epithelial cells. Clinical and experimental allergy : journal of the British Society for Allergy and Clinical Immunology. 2014;44(1):20-8.

47. Parsons KS, Hsu AC, Wark PA. TLR3 and MDA5 signalling, although not expression, is impaired in asthmatic epithelial cells in response to rhinovirus infection. Clinical and experimental allergy : journal of the British Society for Allergy and Clinical Immunology. 2014;44(1):91-101.

48. Schwantes EA, Manthei DM, Denlinger LC, Evans MD, Gern JE, Jarjour NN, et al. Interferon gene expression in sputum cells correlates with the Asthma Index Score during virus-induced exacerbations. Clinical and experimental allergy : journal of the British Society for Allergy and Clinical Immunology. 2014;44(6):813-21.

49. Agrawal R, Wisniewski J, Yu MD, Kennedy JL, Platts-Mills T, Heymann PW, et al. Infection with human rhinovirus 16 promotes enhanced IgE responsiveness in basophils of atopic asthmatics. Clinical and experimental allergy : journal of the British Society for Allergy and Clinical Immunology. 2014;44(10):1266-73.

50. Rohde G, Message SD, Haas JJ, Kebadze T, Parker H, Laza-Stanca V, et al. CXC chemokines and antimicrobial peptides in rhinovirus-induced experimental asthma exacerbations. Clinical and experimental allergy : journal of the British Society for Allergy and Clinical Immunology. 2014;44(7):930-9.

51. Manthei DM, Schwantes EA, Mathur SK, Guadarrama AG, Kelly EA, Gern JE, et al. Nasal lavage VEGF and TNF-alpha levels during a natural cold predict asthma exacerbations. Clinical and experimental allergy : journal of the British Society for Allergy and Clinical Immunology. 2014;44(12):1484-93.

52. Randolph AG, Yip WK, Falkenstein-Hagander K, Weiss ST, Janssen R, Keisling S, et al. Vitamin D-binding protein haplotype is associated with hospitalization for RSV bronchiolitis. Clinical and experimental allergy : journal of the British Society for Allergy and Clinical Immunology. 2014;44(2):231-7.

53. Michaud B, Gouvis-Echraghi R, Candon S, Couderc R, Jais JP, Bach JF, et al. Quantification of circulating house dust mite-specific IL-4- and IL-13-secreting T cells correlates with rhinitis severity in asthmatic children and varies with the seasons. Clinical and experimental allergy : journal of the British Society for Allergy and Clinical Immunology. 2014;44(2):222-30.

54. Darsow U, Brockow K, Pfab F, Jakob T, Petersson CJ, Borres MP, et al. Allergens. Heterogeneity of molecular sensitization profiles in grass pollen allergy--implications for immunotherapy? Clinical and experimental allergy : journal of the British Society for Allergy and Clinical Immunology. 2014;44(5):778-86.

55. Aasbjerg K, Backer V, Lund G, Holm J, Nielsen NC, Holse M, et al. Immunological comparison of allergen immunotherapy tablet treatment and subcutaneous immunotherapy against grass allergy. Clinical and experimental allergy : journal of the British Society for Allergy and Clinical Immunology. 2014;44(3):417-28.

56. Bohle B. Immune mechanisms of SCIT and SLIT: facing possible differences? Clinical and experimental allergy : journal of the British Society for Allergy and Clinical Immunology. 2014;44(3):304-6.

57. Calderon MA, Bernstein DI, Blaiss M, Andersen JS, Nolte H. A comparative analysis of symptom and medication scoring methods used in clinical trials of sublingual immunotherapy 
for seasonal allergic rhinitis. Clinical and experimental allergy : journal of the British Society for Allergy and Clinical Immunology. 2014;44(10):1228-39.

58. Antico A. Long-term adherence to sublingual therapy: literature review and suggestions for management strategies based on patients' needs and preferences. Clinical and experimental allergy : journal of the British Society for Allergy and Clinical Immunology. 2014;44(11):1314-26.

59. Pichler U, Hauser M, Hofer H, Himly M, Hoflehner E, Steiner M, et al. Allergen hybrids next generation vaccines for Fagales pollen immunotherapy. Clinical and experimental allergy : journal of the British Society for Allergy and Clinical Immunology. 2014;44(3):438-49.

60. Scheerens H, Arron JR, Zheng Y, Putnam WS, Erickson RW, Choy DF, et al. The effects of lebrikizumab in patients with mild asthma following whole lung allergen challenge. Clinical and experimental allergy : journal of the British Society for Allergy and Clinical Immunology. 2014;44(1):38-46.

61. Neighbour H, Boulet LP, Lemiere C, Sehmi R, Leigh R, Sousa AR, et al. Safety and efficacy of an oral CCR3 antagonist in patients with asthma and eosinophilic bronchitis: a randomized, placebo-controlled clinical trial. Clinical and experimental allergy : journal of the British Society for Allergy and Clinical Immunology. 2014;44(4):508-16.

62. Gauvreau GM, Boulet LP, Cockcroft DW, FitzGerald JM, Mayers I, Carlsten C, et al. OX40L blockade and allergen-induced airway responses in subjects with mild asthma. Clinical and experimental allergy : journal of the British Society for Allergy and Clinical Immunology. 2014;44(1):29-37.

63. Leaker BR, Barnes PJ, O'Connor BJ, Ali FY, Tam P, Neville J, et al. The effects of the novel SHIP1 activator AQX-1125 on allergen-induced responses in mild-to-moderate asthma. Clinical and experimental allergy : journal of the British Society for Allergy and Clinical Immunology. 2014;44(9):1146-53.

64. Shiraishi Y, Takeda K, Domenico J, Gelfand EW. Role of prostaglandin D2 and CRTH2 blockade in early- and late-phase nasal responses. Clinical and experimental allergy : journal of the British Society for Allergy and Clinical Immunology. 2014;44(8):1076-82.

65. Diamant Z, Sidharta PN, Singh D, O'Connor BJ, Zuiker R, Leaker BR, et al. Setipiprant, a selective CRTH2 antagonist, reduces allergen-induced airway responses in allergic asthmatics. Clinical and experimental allergy : journal of the British Society for Allergy and Clinical Immunology. 2014;44(8):1044-52.

66. Royce SG, Lim CX, Patel KP, Wang B, Samuel CS, Tang ML. Intranasally administered serelaxin abrogates airway remodelling and attenuates airway hyperresponsiveness in allergic airways disease. Clinical and experimental allergy : journal of the British Society for Allergy and Clinical Immunology. 2014;44(11):1399-408.

67. Kavanagh $\mathrm{H}$, Mahon BP. Allogeneic mesenchymal stem cells prevent allergic airway inflammation by inducing murine regulatory T cells. Allergy. 2011;66(4):523-31.

68. Trzil JE, Masseau I, Webb TL, Chang CH, Dodam JR, Cohn LA, et al. Long-term evaluation of mesenchymal stem cell therapy in a feline model of chronic allergic asthma. Clinical and experimental allergy : journal of the British Society for Allergy and Clinical Immunology. 2014;44(12):1546-57.

69. Jun YJ, Park SJ, Hwang JW, Kim TH, Jung KJ, Jung JY, et al. Differential expression of 11beta-hydroxysteroid dehydrogenase type 1 and 2 in mild and moderate/severe persistent allergic nasal mucosa and regulation of their expression by Th2 cytokines: asthma and rhinitis. Clinical and experimental allergy : journal of the British Society for Allergy and Clinical Immunology. 2014;44(2):197-211.

70. Westergaard CG, Porsbjerg C, Backer V. The effect of smoking cessation on airway inflammation in young asthma patients. Clinical and experimental allergy : journal of the British Society for Allergy and Clinical Immunology. 2014;44(3):353-61. 
71. Pizzulli A, Perna S, Florack J, Pizzulli A, Giordani P, Tripodi S, et al. The impact of telemonitoring on adherence to nasal corticosteroid treatment in children with seasonal allergic rhinoconjunctivitis. Clinical and experimental allergy : journal of the British Society for Allergy and Clinical Immunology. 2014;44(10):1246-54.

72. Manoharan A, Lipworth BJ, Craig E, Jackson C. The potential role of direct and indirect bronchial challenge testing to identify overtreatment of community managed asthma. Clinical and experimental allergy : journal of the British Society for Allergy and Clinical Immunology. 2014;44(10):1240-5.

73. Jyonouchi S, Smith CL, Saretta F, Abraham V, Ruymann KR, ModayurChandramouleeswaran $\mathrm{P}$, et al. Invariant natural killer T cells in children with eosinophilic esophagitis. Clinical and experimental allergy : journal of the British Society for Allergy and Clinical Immunology. 2014;44(1):58-68.

74. Macglashan D, Jr., Moore G, Muchhal U. Regulation of IgE-mediated signalling in human basophils by CD32b and its role in Syk down-regulation: basic mechanisms in allergic disease. Clinical and experimental allergy : journal of the British Society for Allergy and Clinical Immunology. 2014;44(5):713-23.

75. Okayama Y, Matsuda A, Kashiwakura JI, Sasaki-Sakamoto T, Nunomura S, Shimokawa $\mathrm{T}$, et al. Highly expressed cytoplasmic FcepsilonRIbeta in human mast cells functions as a negative regulator of the FcRgamma-mediated cell activation signal. Clinical and experimental allergy : journal of the British Society for Allergy and Clinical Immunology. 2014;44(2):23849.

76. Yang W, Schmid E, Nurbaeva MK, Szteyn K, Leibrock C, Yan J, et al. Role of acid sphingomyelinase in the regulation of mast cell function. Clinical and experimental allergy : journal of the British Society for Allergy and Clinical Immunology. 2014;44(1):79-90. 77. Strombeck A, Rabe H, Lundell AC, Andersson K, Johansen S, Adlerberth I, et al. High proportions of FOXP3(+) CD25(high) T cells in neonates are positively associated with allergic sensitization later in childhood. Clinical and experimental allergy : journal of the British Society for Allergy and Clinical Immunology. 2014;44(7):940-52.

78. Meulenbroek LA, Oliveira S, den Hartog Jager CF, Klemans RJ, Lebens AF, van Baalen T, et al. The degree of whey hydrolysis does not uniformly affect in vitro basophil and $\mathrm{T}$ cell responses of cow's milk-allergic patients. Clinical and experimental allergy : journal of the British Society for Allergy and Clinical Immunology. 2014;44(4):529-39.

79. Jarvinen KM, Westfall JE, Seppo MS, James AK, Tsuang AJ, Feustel PJ, et al. Role of maternal elimination diets and human milk IgA in the development of cow's milk allergy in the infants. Clinical and experimental allergy : journal of the British Society for Allergy and Clinical Immunology. 2014;44(1):69-78.

80. Haahtela T, Burbach GJ, Bachert C, Bindslev-Jensen C, Bonini S, Bousquet J, et al. Clinical relevance is associated with allergen-specific wheal size in skin prick testing. Clinical and experimental allergy : journal of the British Society for Allergy and Clinical Immunology. 2014;44(3):407-16.

81. DunnGalvin A, Daly D, Cullinane C, Stenke E, Keeton D, Erlewyn-Lajeunesse M, et al. Highly accurate prediction of food challenge outcome using routinely available clinical data. The Journal of allergy and clinical immunology. 2011;127(3):633-9 e1-3.

82. Preece K, Bhatia R, Belcher J, Patchett K, McElduff P, Collison A, et al. The fraction of exhaled nitric oxide improves prediction of clinical allergic reaction to peanut challenge in children. Clinical and experimental allergy : journal of the British Society for Allergy and Clinical Immunology. 2014;44(3):371-80.

83. Waeckerle-Men Y, Liang Y, von Moos S, Kundig TM, Johansen P. Multivalent paediatric allergy vaccines protect against allergic anaphylaxis in mice. Clinical and experimental allergy : journal of the British Society for Allergy and Clinical Immunology. 2014;44(3):429-37. 
84. Dioszeghy V, Mondoulet L, Dhelft V, Ligouis M, Puteaux E, Dupont C, et al. The regulatory $\mathrm{T}$ cells induction by epicutaneous immunotherapy is sustained and mediates longterm protection from eosinophilic disorders in peanut-sensitized mice. Clinical and experimental allergy : journal of the British Society for Allergy and Clinical Immunology. 2014;44(6):867-81.

85. Linhart B, Narayanan M, Focke-Tejkl M, Wrba F, Vrtala S, Valenta R. Prophylactic and therapeutic vaccination with carrier-bound Bet $\mathrm{v} 1$ peptides lacking allergen-specific $\mathrm{T}$ cell epitopes reduces Bet $\mathrm{v}$ 1-specific $\mathrm{T}$ cell responses via blocking antibodies in a murine model for birch pollen allergy. Clinical and experimental allergy : journal of the British Society for Allergy and Clinical Immunology. 2014;44(2):278-87.

86. West CE, Jenmalm MC, Prescott SL. The gut microbiota and its role in the development of allergic disease: a wider perspective. Clinical and experimental allergy : journal of the British Society for Allergy and Clinical Immunology. 2015;45(1):43-53.

87. Wickens K, Stanley TV, Mitchell EA, Barthow C, Fitzharris P, Purdie G, et al. Early supplementation with Lactobacillus rhamnosus HN001 reduces eczema prevalence to 6 years: does it also reduce atopic sensitization? Clinical and experimental allergy : journal of the British Society for Allergy and Clinical Immunology. 2013;43(9):1048-57.

88. Morgan AR, Han DY, Wickens K, Barthow C, Mitchell EA, Stanley TV, et al. Differential modification of genetic susceptibility to childhood eczema by two probiotics. Clinical and experimental allergy : journal of the British Society for Allergy and Clinical Immunology. 2014;44(10):1255-65.

89. van Drongelen V, Haisma EM, Out-Luiting JJ, Nibbering PH, El Ghalbzouri A. Reduced filaggrin expression is accompanied by increased Staphylococcus aureus colonization of epidermal skin models. Clinical and experimental allergy : journal of the British Society for Allergy and Clinical Immunology. 2014;44(12):1515-24.

90. Minai-Fleminger Y, Gangwar RS, Migalovich-Sheikhet H, Seaf M, Leibovici V, Hollander $\mathrm{N}$, et al. The CD48 receptor mediates Staphylococcus aureus human and murine eosinophil activation. Clinical and experimental allergy : journal of the British Society for Allergy and Clinical Immunology. 2014;44(11):1335-46.

91. Nwaru BI, Craig LC, Allan K, Prabhu N, Turner SW, McNeill G, et al. Breastfeeding and introduction of complementary foods during infancy in relation to the risk of asthma and atopic diseases up to 10 years. Clin Exp Allergy. 2013;43(11):1263-73.

92. Matheson MC, Allen KJ, Tang ML. Understanding the evidence for and against the role of breastfeeding in allergy prevention. Clin Exp Allergy. 2012;42(6):827-51.

93. Morales E, Garcia-Esteban R, Guxens M, Guerra S, Mendez M, Molto-Puigmarti C, et al. Effects of prolonged breastfeeding and colostrum fatty acids on allergic manifestations and infections in infancy. Clin Exp Allergy. 2012;42(6):918-28.

94. Orivuori L, Loss G, Roduit C, Dalphin JC, Depner M, Genuneit J, et al. Soluble immunoglobulin A in breast milk is inversely associated with atopic dermatitis at early age: the PASTURE cohort study. Clinical and experimental allergy : journal of the British Society for Allergy and Clinical Immunology. 2014;44(1):102-12.

95. Dehlink E, Yen E, Leichtner AM, Hait EJ, Fiebiger E. First evidence of a possible association between gastric acid suppression during pregnancy and childhood asthma: a population-based register study. Clin Exp Allergy. 2009;39(2):246-53.

96. Mulder B, Schuiling-Veninga CC, Bos HJ, De Vries TW, Jick SS, Hak E. Prenatal exposure to acid-suppressive drugs and the risk of allergic diseases in the offspring: a cohort study. Clinical and experimental allergy : journal of the British Society for Allergy and Clinical Immunology. 2014;44(2):261-9.

97. Sharpe R, Thornton CR, Osborne NJ. Modifiable factors governing indoor fungal diversity and risk of asthma. Clinical and experimental allergy : journal of the British Society for Allergy and Clinical Immunology. 2014;44(5):631-41. 
98. Amberbir A, Medhin G, Abegaz WE, Hanlon C, Robinson K, Fogarty A, et al. Exposure to Helicobacter pylori infection in early childhood and the risk of allergic disease and atopic sensitization: a longitudinal birth cohort study. Clinical and experimental allergy : journal of the British Society for Allergy and Clinical Immunology. 2014;44(4):563-71.

99. Pritchard DI, Blount DG, Schmid-Grendelmeier P, Till SJ. Parasitic worm therapy for allergy: is this incongruous or avant-garde medicine? Clin Exp Allergy. 2012;42(4):505-12. 100. Obeng BB, Amoah AS, Larbi IA, de Souza DK, Uh HW, Fernandez-Rivas M, et al. Schistosome infection is negatively associated with mite atopy, but not wheeze and asthma in Ghanaian schoolchildren. Clinical and experimental allergy : journal of the British Society for Allergy and Clinical Immunology. 2014;44(7):965-75.

101. Gonzalez-Quintela A, Dam Laursen AS, Vidal C, Skaaby T, Gude F, Linneberg A. IgE antibodies to alpha-gal in the general adult population: relationship with tick bites, atopy, and cat ownership. Clinical and experimental allergy : journal of the British Society for Allergy and Clinical Immunology. 2014;44(8):1061-8.

102. Vetander M, Ly DH, Hakansson N, Lilja G, Nilsson C, Ostblom E, et al. Recurrent reactions to food among children at paediatric emergency departments: epidemiology of allergic disease. Clinical and experimental allergy : journal of the British Society for Allergy and Clinical Immunology. 2014;44(1):113-20.

103. Skaaby T, Husemoen LL, Thuesen BH, Hammer-Helmich L, Linneberg A. Atopy and cause-specific mortality. Clinical and experimental allergy : journal of the British Society for Allergy and Clinical Immunology. 2014;44(11):1361-70.

104. Elmose C, Sverrild A, van der Sluis S, Kyvik KO, Backer V, Thomsen SF. Genetic factors explain half of all variance in serum eosinophil cationic protein. Clinical and experimental allergy : journal of the British Society for Allergy and Clinical Immunology. 2014;44(12):152530 .

105. Pavord ID, Wardlaw AJ. The A to E of airway disease. Clin Exp Allergy. 2010;40(1):62-

7.

106. Gulen T, Hagglund H, Dahlen B, Nilsson G. High prevalence of anaphylaxis in patients with systemic mastocytosis - a single-centre experience. Clinical and experimental allergy : journal of the British Society for Allergy and Clinical Immunology. 2014;44(1):121-9.

107. Gulen T, Hagglund H, Sander B, Dahlen B, Nilsson G. The presence of mast cell clonality in patients with unexplained anaphylaxis. Clinical and experimental allergy : journal of the British Society for Allergy and Clinical Immunology. 2014;44(9):1179-87.

108. Valent P. Risk factors and management of severe life-threatening anaphylaxis in patients with clonal mast cell disorders. Clinical and experimental allergy : journal of the British Society for Allergy and Clinical Immunology. 2014;44(7):914-20.

109. Rueff F, Vos B, Oude Elberink J, Bender A, Chatelain R, Dugas-Breit S, et al. Predictors of clinical effectiveness of Hymenoptera venom immunotherapy. Clinical and experimental allergy : journal of the British Society for Allergy and Clinical Immunology. 2014;44(5):73646.

110. Stoevesandt J, Hain J, Stolze I, Kerstan A, Trautmann A. Angiotensin-converting enzyme inhibitors do not impair the safety of Hymenoptera venom immunotherapy build-up phase. Clinical and experimental allergy : journal of the British Society for Allergy and Clinical Immunology. 2014;44(5):747-55.

111. Slade CA, Douglass JA. Changing practice: no need to stop ACE inhibition for venom immunotherapy. Clinical and experimental allergy : journal of the British Society for Allergy and Clinical Immunology. 2014;44(5):617-9.

112. Berroa F, Lafuente A, Javaloyes G, Ferrer M, Moncada R, Goikoetxea MJ, et al. The usefulness of plasma histamine and different tryptase cut-off points in the diagnosis of peranaesthetic hypersensitivity reactions. Clinical and experimental allergy : journal of the British Society for Allergy and Clinical Immunology. 2014;44(2):270-7. 
113. Vazquez-Ortiz M, Alvaro M, Piquer M, Dominguez O, Machinena A, Martin-Mateos MA, et al. Baseline specific IgE levels are useful to predict safety of oral immunotherapy in eggallergic children. Clinical and experimental allergy : journal of the British Society for Allergy and Clinical Immunology. 2014;44(1):130-41.

114. Vazquez-Ortiz M, Pascal M, Jimenez-Feijoo R, Lozano J, Giner MT, Alsina L, et al. Ovalbumin-specific IgE/IgG4 ratio might improve the prediction of cooked and uncooked egg tolerance development in egg-allergic children. Clinical and experimental allergy : journal of the British Society for Allergy and Clinical Immunology. 2014;44(4):579-88.

115. Vazquez-Ortiz M, Alvaro M, Piquer M, Dominguez O, Machinena A, Martin-Mateos MA, et al. Predicting reactions severity at challenge in egg-allergic patients. Clinical and experimental allergy : journal of the British Society for Allergy and Clinical Immunology. 2014;44(8):1096-7.

116. Tosca MA, Pistorio A, Accogli A, Silvestri M, Rossi GA, Ciprandi G. Egg allergy: the relevance of molecular-based allergy diagnostics. Clinical and experimental allergy : journal of the British Society for Allergy and Clinical Immunology. 2014;44(8):1094-5.

117. Luyt D, Ball H, Makwana N, Green MR, Bravin K, Nasser SM, et al. BSACI guideline for the diagnosis and management of cow's milk allergy. Clinical and experimental allergy : journal of the British Society for Allergy and Clinical Immunology. 2014;44(5):642-72. 118. Fox AT, Swan KE, Perkin M, du Toit G, Lack G. The changing pattern of measles, mumps and rubella vaccine uptake in egg-allergic children. Clinical and experimental allergy : journal of the British Society for Allergy and Clinical Immunology. 2014;44(7):999-1002.

119. Ahrens B, Niggemann B, Wahn U, Beyer K. Positive reactions to placebo in children undergoing double-blind, placebo-controlled food challenge. Clinical and experimental allergy : journal of the British Society for Allergy and Clinical Immunology. 2014;44(4):572-8. 120. Masthoff LJ, van Hoffen E, de Reus A, Boonacker CW, Bruijnzeel-Koomen CA, Pasmans SG, et al. Hazelnut allergy differs between children and adults in frequency of severity, aetiology and relevance of diagnostic parameters. Clinical and experimental allergy : journal of the British Society for Allergy and Clinical Immunology. 2014;44(12):1539-45.

121. Turner PJ, Campbell DE. A food allergy syndrome by any other name? Clinical and experimental allergy : journal of the British Society for Allergy and Clinical Immunology. 2014;44(12):1458-60.

122. Epstein J, Warner JO. Recent advances in the pathophysiology and management of eosinophilic oesophagitis. Clinical and experimental allergy : journal of the British Society for Allergy and Clinical Immunology. 2014;44(6):802-12.

123. Leysen J, Uyttebroek A, Sabato V, Bridts CH, De Clerck LS, Ebo DG. Predictive value of allergy tests for neuromuscular blocking agents: tackling an unmet need. Clinical and experimental allergy : journal of the British Society for Allergy and Clinical Immunology. 2014;44(8):1069-75.

124. Leysen J, Sabato V, Bridts C, Ebo DG. Is the use of NMBA dissuaded in individuals who display positive sIgE to QAS? Clinical and experimental allergy : journal of the British Society for Allergy and Clinical Immunology. 2014;44(3):458.

125. Gueant JL, Dong S, Gueant-Rodriguez RM, Blanca M, Mertes PM. Reply to J. Leysen et al. Clinical and experimental allergy : journal of the British Society for Allergy and Clinical Immunology. 2014;44(3):459.

126. Swerts S, Van Gasse A, Leysen J, Faber M, Sabato V, Bridts CH, et al. Allergy to illicit drugs and narcotics. Clinical and experimental allergy : journal of the British Society for Allergy and Clinical Immunology. 2014;44(3):307-18.

127. Trautmann A, Seitz CS, Stoevesandt J, Kerstan A. Aminopenicillin-associated exanthem: lymphocyte transformation testing revisited. Clinical and experimental allergy : journal of the British Society for Allergy and Clinical Immunology. 2014;44(12):1531-8. 
128. Perkins JR, Barrionuevo E, Ranea JA, Blanca M, Cornejo-Garcia JA. Systems biology approaches to enhance our understanding of drug hypersensitivity reactions. Clinical and experimental allergy : journal of the British Society for Allergy and Clinical Immunology. 2014;44(12):1461-72.

129. Arm JP, Bottoli I, Skerjanec A, Floch D, Groenewegen A, Maahs S, et al. Pharmacokinetics, pharmacodynamics and safety of QGE031 (ligelizumab), a novel highaffinity anti-IgE antibody, in atopic subjects. Clinical and experimental allergy : journal of the British Society for Allergy and Clinical Immunology. 2014;44(11):1371-85.

130. Gorissen DM, Rutten NB, Oostermeijer CM, Niers LE, Hoekstra MO, Rijkers GT, et al. Preventive effects of selected probiotic strains on the development of asthma and allergic rhinitis in childhood. The Panda study. Clinical and experimental allergy : journal of the British Society for Allergy and Clinical Immunology. 2014;44(11):1431-3.

131. Toyotome T, Satoh M, Yahiro M, Watanabe A, Nomura F, Kamei K. Glucoamylase is a major allergen of Schizophyllum commune. Clin Exp Allergy. 2014;44(3):450-7.

132. Makela MJ, Eriksson C, Kotaniemi-Syrjanen A, Palosuo K, Marsh J, Borres M, et al. Wheat allergy in children - new tools for diagnostics. Clin Exp Allergy. 2014;44(11):1420-30. 133. Bertelsen RJ, Faeste CK, Granum B, Egaas E, London SJ, Carlsen KH, et al. Food allergens in mattress dust in Norwegian homes - a potentially important source of allergen exposure. Clinical and experimental allergy : journal of the British Society for Allergy and Clinical Immunology. 2014;44(1):142-9.

134. Curin M, Weber M, Thalhamer T, Swoboda I, Focke-Tejkl M, Blatt K, et al. Hypoallergenic derivatives of Fel d 1 obtained by rational reassembly for allergy vaccination and tolerance induction. Clinical and experimental allergy : journal of the British Society for Allergy and Clinical Immunology. 2014;44(6):882-94.

135. Hazebrouck S, Ah-Leung S, Bidat E, Paty E, Drumare MF, Tilleul S, et al. Goat's milk allergy without cow's milk allergy: suppression of non-cross-reactive epitopes on caprine beta-casein. Clinical and experimental allergy : journal of the British Society for Allergy and Clinical Immunology. 2014;44(4):602-10.

136. van Hoffen E, van der Kleij HP, den Hartog Jager CF, van Doorn WA, Knol EF, Opstelten DJ, et al. Chemical modification of peanut conglutin reduces IgE reactivity but not $T$ cell reactivity in peanut-allergic patients. Clinical and experimental allergy : journal of the British Society for Allergy and Clinical Immunology. 2014;44(12):1558-66.

137. Levin M, Rotthus S, Wendel S, Najafi N, Kallstrom E, Focke-Tejkl M, et al. Multiple independent IgE epitopes on the highly allergenic grass pollen allergen $\mathrm{Phl} p$ 5. Clinical and experimental allergy : journal of the British Society for Allergy and Clinical Immunology. 2014;44(11):1409-19.

138. Levin M, Davies AM, Liljekvist M, Carlsson F, Gould HJ, Sutton BJ, et al. Human IgE against the major allergen Bet v 1--defining an epitope with limited cross-reactivity between different PR-10 family proteins. Clinical and experimental allergy : journal of the British Society for Allergy and Clinical Immunology. 2014;44(2):288-99.

139. Asam C, Batista AL, Moraes AH, de Paula VS, Almeida FC, Aglas L, et al. Bet v 1--a Trojan horse for small ligands boosting allergic sensitization? Clinical and experimental allergy : journal of the British Society for Allergy and Clinical Immunology. 2014;44(8):1083-93. 140. Archila LD, DeLong JH, Wambre E, James EA, Robinson DM, Kwok WW. Grass-specific CD4(+) T-cells exhibit varying degrees of cross-reactivity, implications for allergen-specific immunotherapy. Clinical and experimental allergy : journal of the British Society for Allergy and Clinical Immunology. 2014;44(7):986-98.

141. Moingeon P. The specifics of allergen recognition by CD4(+) T lymphocytes at the epitope level. Clinical and experimental allergy : journal of the British Society for Allergy and Clinical Immunology. 2014;44(7):898-900. 
142. Costa J, Carrapatoso I, Oliveira MB, Mafra I. Walnut allergens: molecular characterization, detection and clinical relevance. Clinical and experimental allergy : journal of the British Society for Allergy and Clinical Immunology. 2014;44(3):319-41.

143. Davies JM. Grass pollen allergens globally: the contribution of subtropical grasses to burden of allergic respiratory diseases. Clinical and experimental allergy : journal of the British Society for Allergy and Clinical Immunology. 2014;44(6):790-801. 